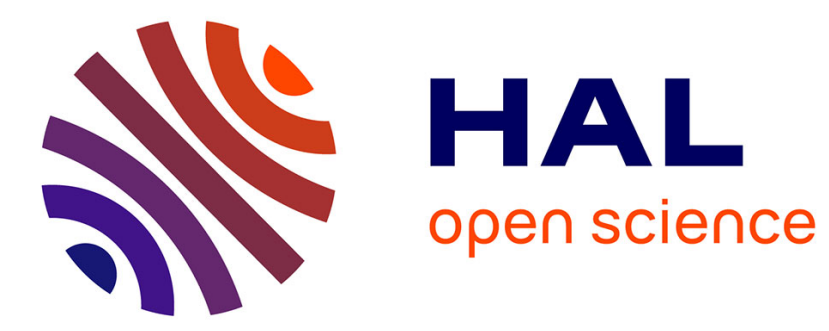

\title{
Fluids and their mechanics in tumour transit: shaping metastasis
}

\author{
Gautier Follain, David Herrmann, Sebastien Harlepp, Vincent Hyenne, Nael \\ Osmani, Sean C Warren, Paul Timpson, Jacky Goetz
}

\section{To cite this version:}

Gautier Follain, David Herrmann, Sebastien Harlepp, Vincent Hyenne, Nael Osmani, et al.. Fluids and their mechanics in tumour transit: shaping metastasis. Nature Reviews Cancer, 2019. hal-02409229

\section{HAL Id: hal-02409229 \\ https://hal.science/hal-02409229}

Submitted on 13 Dec 2019

HAL is a multi-disciplinary open access archive for the deposit and dissemination of scientific research documents, whether they are published or not. The documents may come from teaching and research institutions in France or abroad, or from public or private research centers.
L'archive ouverte pluridisciplinaire HAL, est destinée au dépôt et à la diffusion de documents scientifiques de niveau recherche, publiés ou non, émanant des établissements d'enseignement et de recherche français ou étrangers, des laboratoires publics ou privés. 


\section{REVIEWS}

\section{Fluids and their mechanics in tumour transit: shaping metastasis}

Gautier Follain 1,2,3,7, David Herrmann ${ }^{4,5,7}$, Sébastien Harlepp ${ }^{1,2,3,7}$, Vincent Hyenne ${ }^{1,2,3,6,7}$, Naël Osmani ${ }^{1,2,3,7}$, Sean C. Warren (10) ${ }^{4,5}$, Paul Timpson ${ }^{4,5 *}$ and Jacky G. Goetz (1) ${ }^{1,2,3 *}$

Abstract | Metastasis is a dynamic succession of events involving the dissemination of tumour cells to distant sites within the body, ultimately reducing the survival of patients with cancer. To colonize distant organs and, therefore, systemically disseminate within the organism, cancer cells and associated factors exploit several bodily fluid systems, which provide a natural transportation route. Indeed, the flow mechanics of the blood and lymphatic circulatory systems can be co-opted to improve the efficiency of cancer cell transit from the primary tumour, extravasation and metastatic seeding. Flow rates, vessel size and shear stress can all influence the survival of cancer cells in the circulation and control organotropic seeding patterns. Thus, in addition to using these fluids as a means to travel throughout the body, cancer cells exploit the underlying physical forces within these fluids to successfully seed distant metastases. In this Review, we describe how circulating tumour cells and tumour-associated factors leverage bodily fluids, their underlying forces and imposed stresses during metastasis. As the contribution of bodily fluids and their mechanics raises interesting questions about the biology of the metastatic cascade, an improved understanding of this process might provide a new avenue for targeting cancer cells in transit.

'INSERM UMR_S1109, Tumor Biomechanics, Strasbourg, France.

2Université de Strasbourg, Strasbourg, France.

${ }^{3}$ Fédération de Médecine Translationnelle de Strasbourg (FMTS), Strasbourg, France.

${ }^{4}$ The Kinghorn Cancer Centre, Garvan Institute of Medical

Research, Sydney, New South Wales, Australia.

${ }^{5}$ St. Vincent's Clinical School, Faculty of Medicine, University of New South Wales, Sydney, New South Wales, Australia. ${ }^{6}$ CNRS SNC 505, Strasbourg, France.

${ }^{7}$ These authors contributed equally: Gautier Follain David Herrmann, Sébastien Harlepp, Vincent Hyenne, Naël Osmani.

*e-mail:p.timpson@garvan. org.au; jacky.goetz@inserm.fr

https://doi.org/10.1038 s41568-019-0221-x
The Greek phrase 'Panta Rhei', which literally translates as 'everything flows', is a philosophical concept that is often attributed to the presocratic Greek philosopher Heraclitus (circa $500 \mathrm{BC}$ ) and was an attempt to explain the ever-changing nature of life. Work over the past decades has shown that this notion might also apply to tumour metastasis, a complex multistep process whereby malignant tumours shed invasive cells with metastatic capacity that need to overcome many obstacles (for example, immune surveillance) for successful outgrowth at secondary sites ${ }^{1}$. However, in addition to the multiple molecular pathways driving metastasis, a plethora of studies conducted over the past two decades strongly suggest that mechanical forces are also responsible for tumour progression and response to classical therapies ${ }^{2-4}$. Among these forces, fluid-based mechanics have progressively entered the scene. Indeed, on their way to forming a metastasis, tumour cells and tumoursecreted factors use and exploit three main bodily fluids - blood, lymph and interstitial fluid ${ }^{5-7}$ (FIG. 1a). Circulating tumour cells (CTCs) and their associated material, including soluble factors and extracellular vesicles (EVs), can directly travel through the haematogenous system $^{1,8}$ or sequentially use both the lymphatic and blood vasculature to colonize distant organs ${ }^{9-11}$ (FIG. 1 b). This notion that fluid-based mechanics can shape metastasis originated from an early pivotal study that coined the 'hemodynamic theory', which showed that arterial blood flow in certain organs can be positively correlated with the frequency and patterns of metasta$\operatorname{sis}^{12}$, supporting a link between flow mechanics and the secondary site of metastasis.

When transported in fluids, CTCs are subjected to and exploit various mechanical forces, which can influence their fate in many ways. For instance, high shear forces exerted on CTCs can induce mechanical stress, leading to cell fragmentation and death ${ }^{13}$, whereas intermediate shear forces have been shown to favour CTC intravascular arrest and extravasation ${ }^{14}$. Thus, an improved understanding of the mechanical forces encountered by CTCs and tumour-associated material in fluids is crucial for fully elucidating the metastatic cascade and delineating vulnerable CTC states for therapeutic intervention.

In this Review, we describe how circulating tumourderived material (cells and associated factors) use bodily fluids, their underlying forces and the resultant stresses they impose as a natural means to escape from primary tumours, travel throughout the body, prime pre-metastatic niches (PMNs) and successfully seed distant metastases. We briefly discuss key flowrelated aspects of tumour growth and invasion that have received considerable attention ${ }^{2,6,7}$ and discuss how these modes of flow are essential means of transport 
a

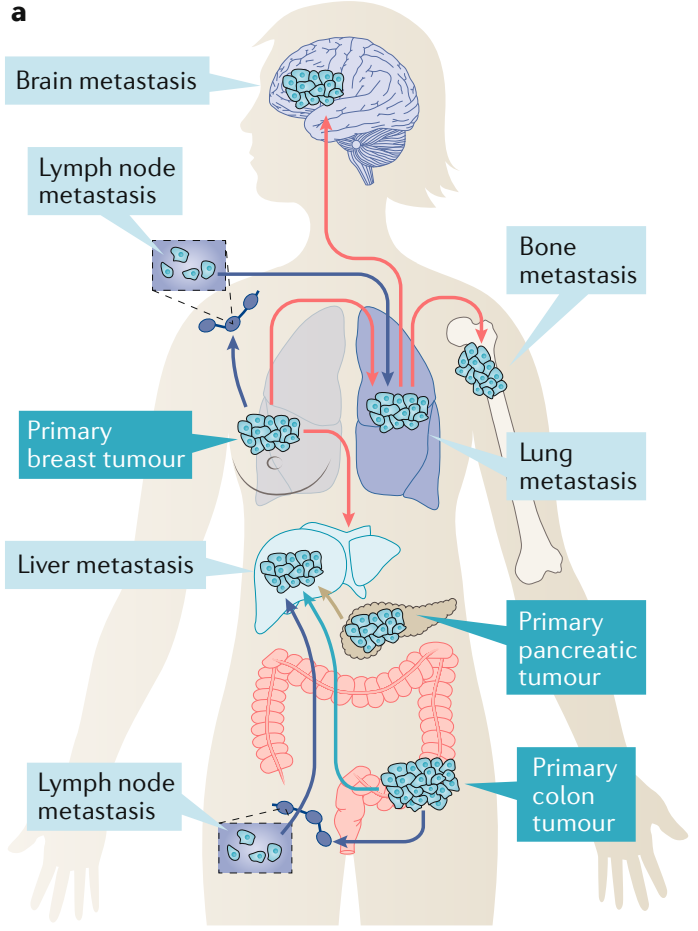

b

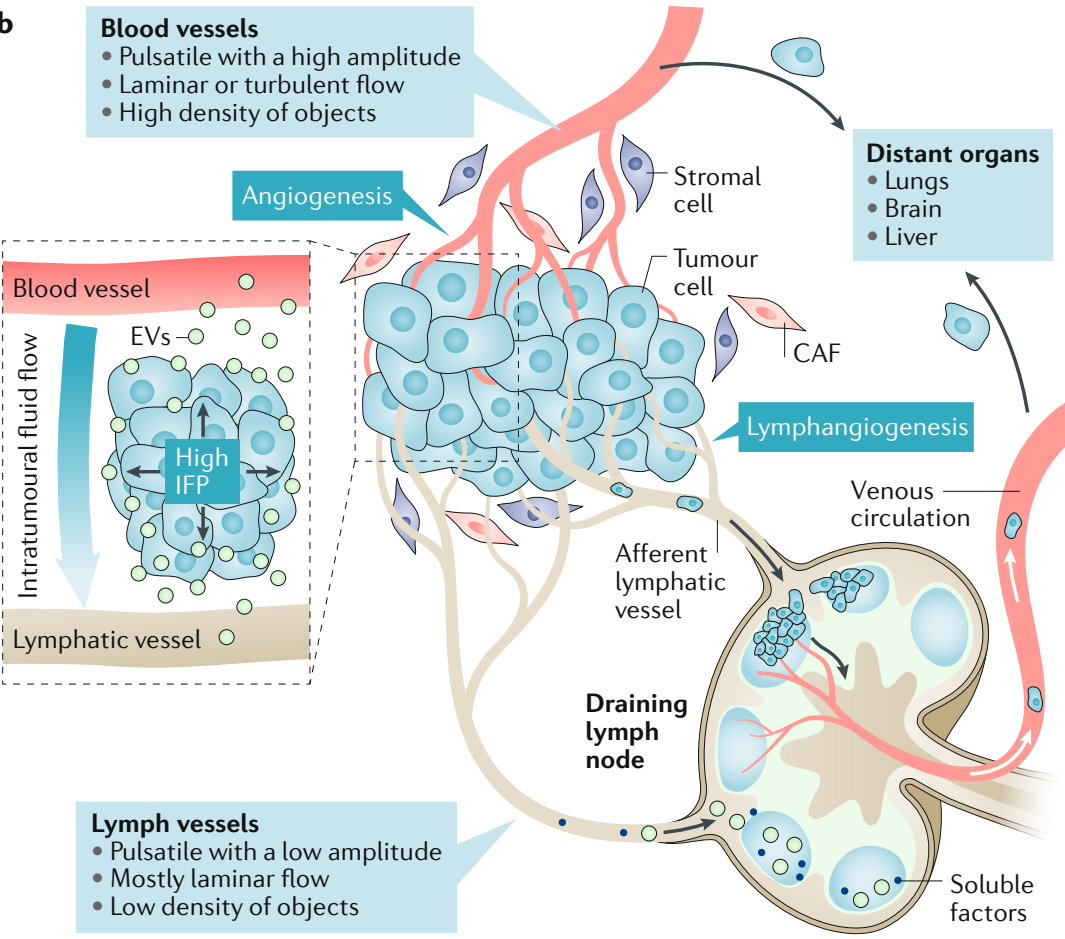

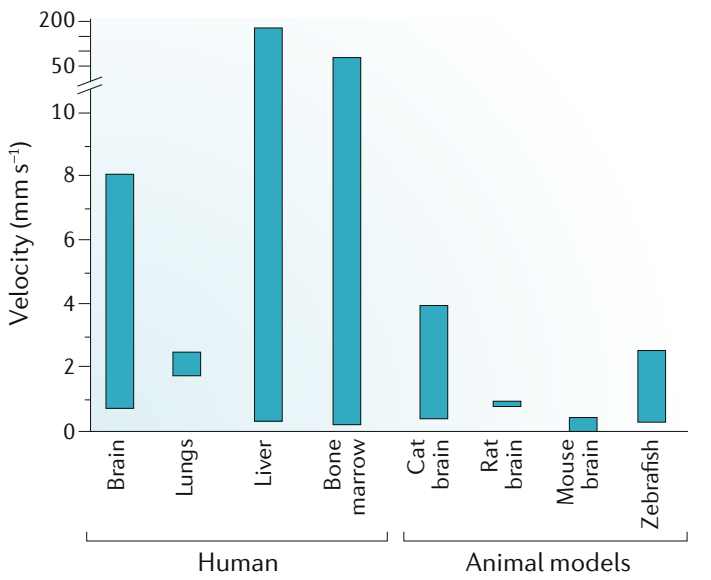

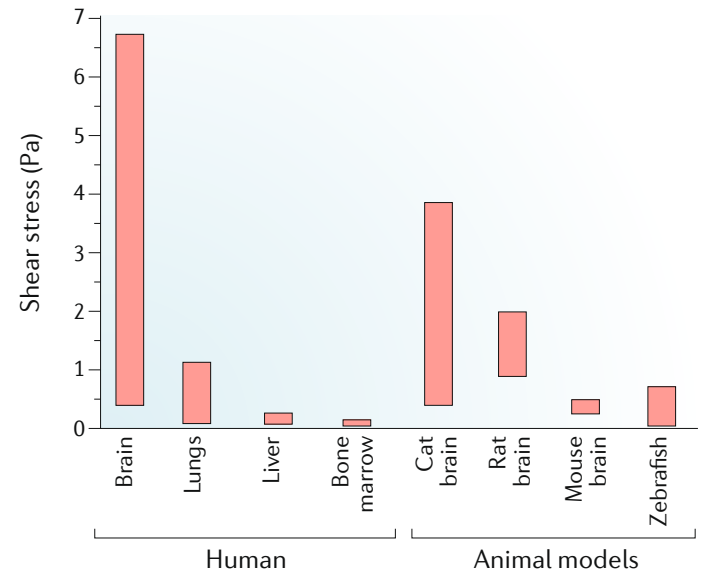

Fluids

Substances devoid of rigidity that continuously deform and do not resist shear stress applied to them.

\section{Interstitial fluid}

Fluid originating from blood capillaries' leakiness that is present around cells, bringing nutrients to these cells and flowing towards lymphatic draining sites, giving rise to interstitial fluid flow.

\section{Circulating tumour cells} (CTCS). Tumour cells that have left their primary tumour and entered the blood or lymphatic circulation (intravasation); to survive and to trave throughout the body, they co-opt this new fluid environment that they are exposed to.

Fig. 1 | Fluid routes orchestrate the metastatic cascade. a | Metastatic dissemination is a non-random process based on biological and mechanical cues. The anatomical plan and corresponding vascular pathways depict how circulating tumour cells (CTCs) use blood, as well as the lymphatic circulation (purple arrows), to reach distant organs, highlighting the common metastatic patterns for colon cancer (blue arrows), breast cancer (red arrows) and pancreatic cancer (brown arrows). b| Interstitial flows allow tumour cells and tumour-derived factors to reach these circulatory systems in the primary tumour microenvironment. Both tumour cells and tumour-derived factors will disseminate in the lymphatic circulation, seed draining lymph nodes and colonize local blood vessels. Ultimately, tumour-derived factors will prime pre-metastatic niches in target organs, where disseminating tumour cells will grow as metastatic colonies upon their haematogenous dissemination. $\mathbf{c}$ | Histograms describing flow parameters, specifically velocity and shear stress, in human organs and various animal models. Values correspond mostly to adult organs, except for zebrafish, in which values correspond to the day 2 post-fertilization stage (see also Supplementary Table 1). CAF, cancer-associated fibroblast; EV, extracellular vesicle; IFP, interstitial fluid pressure.

for tumour-derived material ${ }^{8,15,16}$. In addition, we detail the influence of flow types, patterns, components and flow-associated forces during haematogenous dissemination, with a focus on the last steps of metastasis. We also highlight existing in vitro and in vivo models and multi-scale imaging and biophysical tools available for interrogating fluid mechanics and the intravascular behaviour of CTCs during metastasis. The contribution of fluids, and their mechanics, raises interesting questions about the fate and metastatic potential of CTCs and, therefore, about the biology of the metastatic cascade, opening up an important research area that is often overlooked but that could be amenable to therapeutic targeting in the future. 


\section{Soluble factors}

Proteins (including protein ligands or extracellular matrixmodifying proteins) that are secreted by tumour cells to induce the remodelling of distant sites to facilitate metastatic seeding.

\section{Bodily fluids}

Blood, lymph and interstitial fluid can be described according to their biophysical attributes, which are influenced by their unique composition and characteristics, enabling an estimation of the mechanical stress each fluid can impose on CTCs and other tumour-derived components ${ }^{17,18}$. These interlinked compartments have different flow types (which, among others, are dependent on the value of the dimensionless Reynolds number) and flow rates, which are experienced or exploited by CTCs and/or tumour-secreted material during transit (TABLE 1). For instance, in the lymphatic system, flow is mostly laminar flow, pulsatile with a low amplitude, mainly driven by viscosity and has low velocities ${ }^{19}$.
By contrast, blood has a much higher density of circulating objects (blood cells and other factors) and has higher flow velocities due to cardiac pumping. In addition, blood flow can be pulsatile with a high amplitude and turbulent flow in arteries, whereas flow is mostly laminar in veins ${ }^{20}$. Furthermore, biophysical cues differ according to flow and vessel type (TABLE 1) as well as organ (FIG. 1 c; see Supplementary Table 1). Overall, CTCs and tumour-derived material travelling in the circulation are exposed to shear rate values ranging from $\sim 10 \mathrm{~s}^{-1}$ in the lymph ${ }^{19}$ to $\sim 1,000 \mathrm{~s}^{-1}$ in large arteries ${ }^{20,21}$.

Blood and lymph are also responsible for the interstitial fluid flow that is characteristic of tumours ${ }^{2}$. Interstitial fluid is generated by a high capillary blood

Table 1 | Key features of bodily fluid systems involved in cancer cell transport

\begin{tabular}{|c|c|c|c|c|c|}
\hline Fluid system & Properties & Contents & $\begin{array}{l}\text { Biophysics and } \\
\text { biomechanical } \\
\text { forces }\end{array}$ & Cell behaviour and phenotype & Refs \\
\hline Interstitial fluid & $\begin{array}{l}\text { Laminar flow; flow driven by } \\
\text { gradient of IFP (high in tumour } \\
\text { core, low in periphery); high } \\
\text { density of circulating objects; } \\
\text { shear stress: } 0.1-1 \text { Dyn } \mathrm{cm}^{-2} \text {; } \\
\text { velocities: } 0.001-0.004 \mathrm{~mm} \mathrm{~s}^{-1} \text {; } \\
\text { Reynolds number: } 0.00005-0.0002\end{array}$ & NA & $\begin{array}{l}\text { Darcy's model }^{\mathrm{a}} \\
\text { (convective and }^{\text {diffusive flow) }}\end{array}$ & $\begin{array}{l}\text { Chemokine gradients enhance tumour } \\
\text { cell migration; reduces tumour cell } \\
\text { migration due to downregulation of } \\
\text { MMPs; increases tumour cell invasion and } \\
\text { promotes amoeboid motility of breast } \\
\text { cancer cells; induces overexpression } \\
\text { of integrins, MMPs and ECM proteins; } \\
\text { alters cytoskeletal protein expression; } \\
\text { promotes EMT, characterized by a switch } \\
\text { from keratin to vimentin intermediate } \\
\text { filament expression }\end{array}$ & $\begin{array}{l}5,36-39,41 \\
42,224-227\end{array}$ \\
\hline Lymphatic system & $\begin{array}{l}\text { Laminar flow; pulsatile with low } \\
\text { amplitude at low frequency; flow } \\
\text { driven by viscosity; low density of } \\
\text { circulating objects; shear stress: } \\
0.64-12 \text { Dyn cm }^{-2} \text {; velocities: } \\
0.02-1 \mathrm{~mm} \mathrm{~s}^{-1} \text {; Reynolds number: } \\
0.000033-0.002\end{array}$ & $\begin{array}{l}\text { Cells (for } \\
\text { example, immune } \\
\text { cells and tumour } \\
\text { cells); tumour- } \\
\text { derived acellular } \\
\text { material }\end{array}$ & $\begin{array}{l}\text { Navier-Stokes } \\
\text { equation }^{\mathrm{b}}\end{array}$ & $\begin{array}{l}\text { Promotes cell migration and motility in a } \\
\text { YAP1-dependent manner or supports cell } \\
\text { division in a TAZ-dependent manner }\end{array}$ & $\begin{array}{r}19,100,132 \\
133,228-232\end{array}$ \\
\hline $\begin{array}{l}\text { Haematogenous } \\
\text { system: arteries }\end{array}$ & $\begin{array}{l}\text { Flow driven by cardiac pumping; } \\
\text { laminar to turbulent flow; } \\
\text { pulsatile with high amplitude at } \\
\text { high frequency; high density of } \\
\text { circulating objects; high velocity; } \\
\text { shear stress: } 4-30 \text { Dyn cm }{ }^{-2} \text {; } \\
\text { velocities: } 100-500 \mathrm{~mm} \mathrm{~s}^{-1} \text {; } \\
\text { Reynolds number: } 1-5,000\end{array}$ & \multirow{3}{*}{ 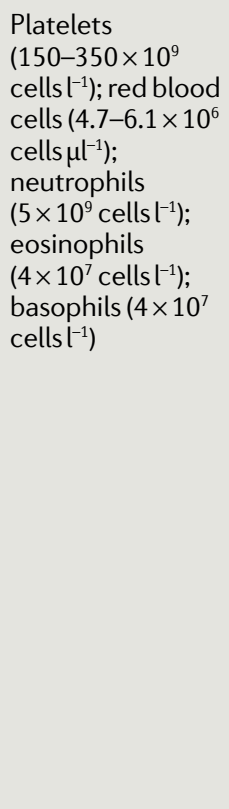 } & \multirow[t]{3}{*}{$\begin{array}{l}\text { Navier-Stokes } \\
\text { equation } \\
\text { with included } \\
\text { fluid-structure } \\
\text { interaction }^{c}\end{array}$} & \multirow{3}{*}{$\begin{array}{l}\text { Decreases cell viability (even if shear } \\
\text { stress resistance is a conserved property } \\
\text { in tumour cells); high shear stress causes } \\
\text { necrosis in }>90 \% \text { of CTCs; interaction with } \\
\text { platelets reduces anoikis and promotes } \\
\text { metastasis by activating YAP1 signalling; } \\
\text { increases expression of adhesion proteins } \\
\text { (CD44 and integrins) in CTCs, allowing } \\
\text { adhesion on endothelial walls when flow } \\
\text { velocity is }<600 \mathrm{~mm} \mathrm{~s}^{-1} \text {; correlation between } \\
\text { cell death and increasing shear stress }\end{array}$} & $\begin{array}{r}78,113-116 \\
233-242\end{array}$ \\
\hline $\begin{array}{l}\text { Haematogenous } \\
\text { system: veins }\end{array}$ & $\begin{array}{l}\text { Flow driven by cardiac pumping; } \\
\text { laminar flow; pulsatile with low } \\
\text { to medium amplitude at medium } \\
\text { frequency; high density of } \\
\text { circulating objects; slow velocity; } \\
\text { shear stress: } 1-4 \text { Dyn } \mathrm{cm}^{-2} \text {; } \\
\text { velocities: } 1-200 \mathrm{~mm} \mathrm{~s}^{-1} \text {; } \\
\text { Reynolds number: } 0.006-100\end{array}$ & & & & $\begin{array}{l}233,234 \\
243,244\end{array}$ \\
\hline $\begin{array}{l}\text { Haematogenous } \\
\text { system: capillaries }\end{array}$ & 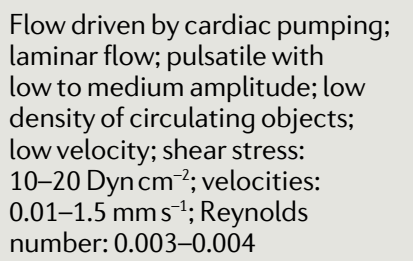 & & & & $\begin{array}{l}233,234 \\
245-247\end{array}$ \\
\hline
\end{tabular}

CTC, circulating tumour cell; ECM, extracellular matrix; EMT, epithelial-mesenchymal transition; IFP, interstitial fluid pressure; MMP, matrix metalloproteinase; $N A$, not available; TAZ, transcriptional co-activator with PDZ-binding motif; YAP1, Yes-associated protein 1 . ${ }^{a} D a r c y$ 's model, $Q=K A \frac{\nabla P}{}$, describes the flow $Q$ of an incompressible fluid with viscosity $\eta$ exerted by a loss in pressure $\Delta P$ through a porous material of area $A$ possessing a hydraulic ${ }^{\eta L}$ 'onductivity $K$. ${ }^{b} T h e$ NavierStokes equation is $\frac{\partial u}{\partial t}+(u . \nabla) u=-\frac{1}{\rho} \nabla P+v \nabla^{2} u$, where $\nabla V=0, \rho$ is density, $v$ is viscosity, $u$ is the velocity vector and $P$ is pressure. ${ }^{c} C o n s i d e r i n g$ distensibility $D$ and area $A$, where $D \cong \frac{\partial}{A} \frac{\partial A}{\partial p}$, and the mass conservation law $A D \frac{\delta p}{\delta t}=-\frac{\partial Q}{\partial x}$. 


\section{Box 1 | Interstitial fluid pressure at primary tumour sites}

Aberrant flow and permeability of intratumoural blood vessels often result in continuous plasma deposition into the extracellular space, which cannot be cleared or drained owing to tumour growth-induced compression of intratumoural lymphatic vessels, leading to high interstitial fluid pressure (IFP) within the tumour ${ }^{34,219}$ (see the figure). Increased lymphangiogenesis in the tumour periphery ${ }^{220}$ then creates a gradient of IFP (high intratumoural IFP and low IFP in the tumour periphery), with interstitial flow from the tumour centre to and beyond the tumour border.

Interstitial flow can promote the distribution of tumour-derived cells, extracellular vesicles (EVs) and molecules into the periphery, whereas high IFP in the tumour core has been shown to limit the efficiency of drug delivery ${ }^{22,33}$. In vitro microfluidic models suggest that interstitial flow can also affect the mode of cell migration and the directionality of cancer cell migration ${ }^{42}$, both directly (by inducing asymmetric focal adhesion distribution 221,222 ) and indirectly (by guiding the differentiation of tumour-supporting stromal cell populations ${ }^{44}$ ).

New approaches to mathematically model IFP at sites that cannot be easily accessed for experimental measurements and manipulation, such as brain tumours ${ }^{223}$, might provide further insight into the role of IFP in tumour progression, metastasis and response to treatment.

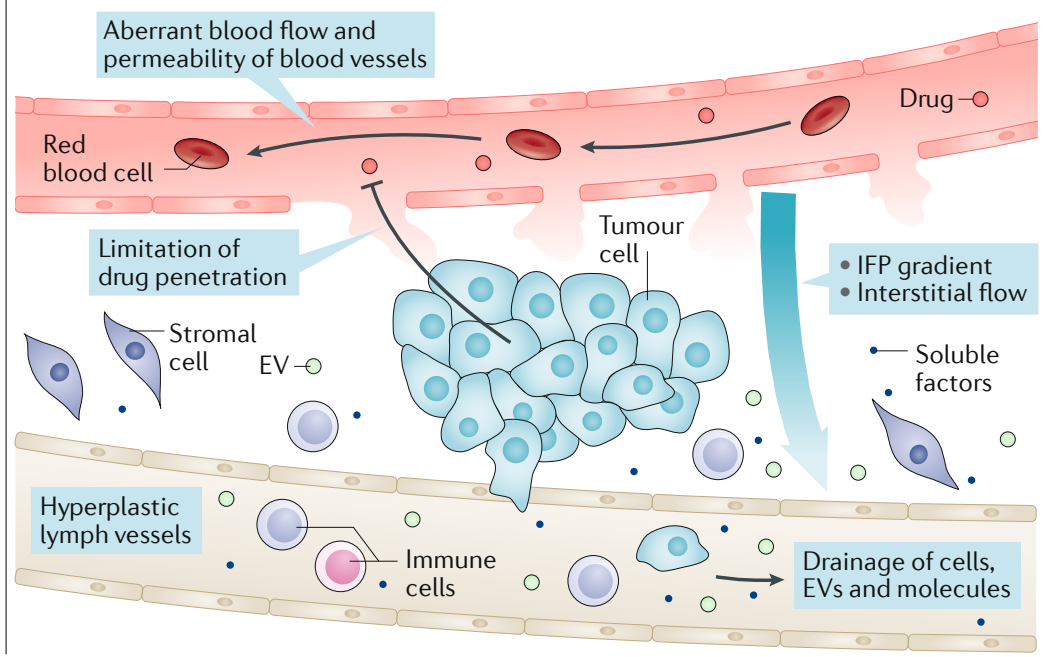

Extracellular vesicles (EVs). Lipid bilayer-delimited particles that serve as cargo for the transfer of nucleic acids, proteins or lipids to distant sites; their membrane composition provides a fingerprint for the targeted priming of specific organs.

Intravascular arrest

The process that precedes cancer cell extravasation, whereby circulating tumour cells become physically

occluded in microvessels and/or actively adhere to the inner endothelial lining of blood vessels at secondary sites.

Pre-metastatic niches (PMNs). A new paradigm for the initiation of metastasis; these are pre-metastatic microenvironments that are seeded and/or educated by tumour-secreted factors, inducing phenotypes that can help secondary tumour development. pressure as well as cellular pressure in the solid tumour ${ }^{22}$ and is drained by the lymphatic system and its primary valves, where the pressure is lower. This directional displacement has been described in a model ${ }^{23}$ based on Darcy's law $w^{24}$ and is mainly linked to the differences in pressure, surface area and hydraulic conductance between these networks. Interestingly, in addition to facilitating the dissemination of tumour cells and tumourassociated material ${ }^{7}$, interstitial fluid pressure (IFP) also has important consequences for drug delivery into the tumour $^{2}$ (BOX 1).

\section{Fluid mechanics in primary tumours}

Solid tumours form a complex microenvironment containing cancer cells, stromal cells, extracellular matrix (ECM), and blood and lymphatic vessels. Tumour growth relies on angiogenesis, which provides oxygen and necessary nutrients through formation of new blood vessels, and lymphangiogenesis, which facilitates removal of excessive fluids and drainage of tumour cells and tumour-secreted factors from the tumour ${ }^{25,26}$ (FIC. 1). In addition, both fluid systems enable the transit of immune cells in and out of tumours, and the lymphatic circulation orchestrates local immune surveillance under the control of neighbouring lymph nodes ${ }^{15,27}$.
Darcy's model explains how differences in IFP within the tumour drive the diffusion and convection of fluids from the blood towards the draining lymphatic vascular system $^{7}$ (BOX 1; TABLE 1). In primary tumours, the IFP gradient is further enhanced by the leakiness of the non-mature tumour-associated blood vasculature ${ }^{28,29}$. In addition, rapid tumour growth creates solid stress, which exposes the tumour-associated vasculature to further vascular squeezing through compression and tension $^{30-32}$ (BOX 1), thereby generating high IFP in the tumour tissue. Indeed, in an autochthonous mouse model of pancreatic ductal adenocarcinoma, intratumoural IFP was more than ninefold higher than IFP measured in matched healthy tissue ${ }^{33}$. Although a high IFP is detectable in the tumour core r $^{33,34}$, IFP levels drop at the tumour periphery, thereby establishing interstitial fluid flow through the peritumoural stroma into the lymphatic vessels ${ }^{7,35}$ (FIG. 1; BOX 1). The interstitial fluid flow results from both convection and diffusion flow towards the periphery ${ }^{36}$, with velocity values of $\sim 0.001-0.004 \mathrm{~mm} \mathrm{~s}^{-1}\left(\mathrm{REFS}^{37-39}\right)$. In parallel, solid stress squeezes blood and lymphatic vessels ${ }^{40}$, thereby hindering oxygenation and homeostasis of the solid tumour. In turn, tumour cells tend to increase the release of pro-angiogenic factors ${ }^{22}$, leading to an aberrant and hyperpermeable blood circuit (low velocity, highly heterogeneous; $\mathrm{BOX} 1$ ), which further contributes to the malignant behaviour of tumour cells.

Several studies have shown that tumour interstitial fluid promotes the migration and/or invasion of tumour cells. Indeed, interstitial convective flow can, for example, increase glioblastoma cell invasion ${ }^{41}$ and promote amoeboid migration of breast cancer cells $s^{42}$ towards the lymphatic drainage, where tumour cells have been shown to escape from the primary tumour with the help of macrophages $^{43}$ (BOX 1). Interstitial fluid flow can also influence stromal cells, for example, by promoting the differentiation of macrophages into polarized populations that can, in turn, increase directional cancer cell migration ${ }^{44}$. In addition, migratory macrophages were shown to switch to sessile perivascular ones and assist tumour cells during intravasation in a mouse model of breast cancer ${ }^{45}$, but whether this process can be influenced by interstitial flow is unknown. Furthermore, cancer cells can move against the convective flow using substrates, such as collagen I fibres, that can promote adoption of mesenchymal phenotypic motility ${ }^{42}$. An elaborate in vitro study also showed that interstitial fluid flow can synergize with luminal vessel flow to enhance tumour cell intravasation within lymphatic vessels ${ }^{46}$; however, whether this also occurs in vivo remains unknown.

By influencing the direction of tumour cell migration, interstitial fluid flow can guide tumour cells and tumour-associated factors to the vicinity of lymphatic or blood vessels. Indeed, it is tempting to suggest that such convection forces, in combination with blood and lymphatic circulations, displace tumour-derived material and cells to favour their directed dissemination (and also the dissemination of tumour-derived soluble factors or EVs) towards the vascular systems or towards the ECM at the periphery, while also limiting therapeutic distribution in solid tumours ${ }^{22}$ (BOX 1). 
Reynolds number

(Re). A dimensionless number proportional to fluid velocity $V$, density $\rho$, the displacement length $L$ and the viscosity $\eta$. It allows one to classify flow types and to determine whether the fluid flow is laminar or turbulent (Re $>1000)$.

\section{Laminar flow}

In fluid dynamics, fluid particles transported in a laminar flow follow smooth directions in layers, with little or no mixing

Viscosity

A measure of the resistance of a fluid to deformation at a given rate that quantifies the frictional force generated by layers of fluids that are in motion. Gases, water and other liquids are considered Newtonian fluids because they display a linear correlation between shear stress and the rate of deformation. When fluids display a non-linear relation between stress and the deformation rate, they are considered non-Newtonian this is the case for blood.

\section{Turbulent flow}

In contrast to laminar flow, turbulent flow is characterized by chaotic changes in pressure and flow velocity that create mixing of the flow paths of displaced particles.

Darcy's law

A physical law that, in the context of cancer progression, is linked to interstitial fluid and to hydraulic conductivity of the environment arising from a convective fluid displacement.

Hydraulic conductance The capacity of a porous material to allow fluid to cross under the effect of pressure differences

Interstitial fluid pressure (IFP). The hydrostatic pressure in the cellular interstice, which, in solid tumours, is often due to vessel leakage and lymphatic drainage.

Lymphangiogenesis The remodelling of existing lymphatic networks to give rise to new lymphatic vessels.

\section{Early dissemination}

Tumours can exploit the flow mechanics of the blood and lymphatic circulatory systems to facilitate the earliest steps of the metastatic cascade, including the intravasation and lymphatic dissemination of malignant tumour cells and tumour-derived factors from the primary site.

Tumour cell intravasation and lymphatic dissemination. Over the past decade, evidence obtained in patients with breast cancer ${ }^{47}$ and colorectal cancer ${ }^{48}$ suggests that tumour dissemination is an event that can also occur in early lesions, rather than being solely restricted to more developed primary tumours. Although this hypothesis needs to be confirmed in other cancer types, such a feature has been confirmed in mouse models of pancreatic cancer $^{49}$ and breast cancer ${ }^{50-52}$, raising the question of early dissemination mechanisms. It should be noted that cell shedding can also occur in mid-to-late-stage tumours, and that the timepoint or interval of tumour cell intravasation and/or metastasis can be cancer-type or patient specific. Although early lesions are less likely to be highly vascularized, the influence of fluid mechanics on intravasation in early versus advanced primary tumours remains to be determined.

Primary tumour cells have two exit routes to escape - some cancer types directly disseminate through the blood vasculature, whereas others spread via the lymphatic circulation (FIG. 1a). Haematogenous dissemination of CTCs follows the successful intravasation of invasive carcinoma cells - either as individual cells (as in the case of spontaneous murine mammary tumours ${ }^{43,52}$ ) or as clusters (which are rare in comparison with single CTCs in patients with breast or prostate cancer ${ }^{53}$ ) - into the vasculature of neighbouring normal tissue or the vasculature formed within the tumours ${ }^{53}$ (FIG. 1 b). How flow mechanics influence the intravasation of single cells versus clusters of tumour cells, and whether this impacts the flow type they favour for initial dissemination, remains to be determined; microfluidic approaches (TABLE 2; see Supplementary Table 2) could be instrumental for answering these questions.

Metastasis to regional lymph nodes often precedes systemic disease and is the most reliable factor for predicting survival in patients with carcinomas ${ }^{54}$. Lymph node metastasis defines poor outcomes in patients with many cancer types (including lung, prostate, breast and colorectal cancer) as it correlates with spread to vital organs $^{55}$. As lymph node metastasis does not cause the death of patients, it is reliably used for staging and predicting cancer progression. Interestingly, tumour cells that have metastasized to the lymph nodes via the lymphatic circulation can transfer to the blood circulation that perfuses the lymphatic organs ${ }^{9,11}$ (FIG. 1a,b). As tumour spread to the lymph nodes often correlates with reduced patient survival ${ }^{56}$, lymph node metastasis is thought to be, in addition to direct vascular dissemination, an intermediate step in the process of life-threatening distant metastasis; however, lymph node dissection is not necessarily beneficial for patients (as is the case for patients with melanoma who have nodal metastasis $^{57}$ ).
Experimental evidence for a mechanism of intermediate transit has been provided in mouse models of melanoma and mammary, colorectal and squamous cell carcinoma ${ }^{9,11}$. Careful tracing of the fate of tumour cells revealed that they initially colonize the cortex of lymph nodes upon draining from the lymphatic circulation through the subcapsular sinus ${ }^{11}$. Here, tumour cells exploit endothelial venules to exit from the lymph node into the blood vasculature before seeding secondary metastases in the lungs, which can also form directly through haematogenous dissemination. Interestingly, when studying the evolutionary history of metastases in the context of colorectal cancer, researchers found two distinct lineage relationships between lymphatic and distant metastases that are intricately linked to fluid routes. For example, in patients with colorectal cancer, phylogenetic analysis of matched primary tumours and metastases showed that, although lymphatic and distant metastases had distinct origins in $65 \%$ of patients, $35 \%$ of distant tumours shared a common metastatic ancestor with lymph node metastases ${ }^{10}$. Whether fluid biomechanics have a role in the initial choice of the fluid route is unknown. However, as flow velocities and shear stress are lower in lymphatic vessels than in blood vessels (in rats) ${ }^{19}$ (TABLE 1; FIG. 2), lymphatic dissemination might be initially less deleterious to CTCs than dissemination through the blood.

Dissemination of tumour-derived factors. In addition to representing routes of rapid escape for tumour cells, lymphatic and blood vessels allow the dissemination of various tumour-secreted factors, including cytokines, chemokines, growth factors, matrix metalloproteinases, circulating tumour DNA, antigens and EVs ${ }^{15,16,58-62}$, which is likely to happen throughout tumour progression. The mechanism by which these factors enter the circulation has not been formally demonstrated, but they are likely to be transported by interstitial fluid and, in contrast to tumour cells with active motility potential, are unlikely to be transported against the flow (FIG. 1 b). Recent advancements in tracking EVs in vivo could be instrumental to identifying these routes of early dissemination ${ }^{63}$. Chemokines have been shown to diffuse down concentration gradients in interstitial fluid and guide dendritic cells towards lymphatic vessels in mice ${ }^{64}$; in tumours, similar mechanisms could favour the dissemination of tumour-secreted factors.

Tumour-secreted factors are found in both the blood and lymphatic circulation, where they, in addition to CTCs, constitute novel targets for early cancer diagnosis or longitudinal monitoring of anticancer treatment response using liquid biopsies ${ }^{65,66}$. Given their short half-life in the circulation $\left(\sim 2 \mathrm{~min}\right.$ for $\mathrm{EVs}^{67,68}$ injected intravenously in mice and $<115$ min for circulating tumour $\mathrm{DNA}^{69}$ in humans) and their high abundance in bodily fluids, it is likely that tumour-secreted factors are constitutively released by tumours. Both physics and biology provide reasons for these short half-lives. The clearance of EVs from the circulation depends on myeloid cells - particularly macrophages in mice and zebrafish $^{70,71}$ and neutrophils in mice ${ }^{72}$ - that are present in blood vessels and on endothelial cells. The small size 
Table 2 | Models for tracking the intravascular dynamics of CTCs

\begin{tabular}{|c|c|c|c|}
\hline Model & Approach & Advantages & Disadvantages \\
\hline Microfluidics & $\begin{array}{l}\text { Cancer cells can be exposed to } \\
\text { tuneable shear stress; channels can } \\
\text { be coated with other cell types or } \\
\text { substrates to study molecular and } \\
\text { cellular interactions of CTCs in } \\
\text { transit }^{78,174}\end{array}$ & $\begin{array}{l}\text { Fast assay; medium to high throughput; } \\
\text { variable pricing depending on setup; } \\
\text { uncomplicated integration of live cell } \\
\text { imaging }\end{array}$ & $\begin{array}{l}\text { Low-fidelity, ex vivo assay; lack } \\
\text { of microenvironment or artificial } \\
\text { microenvironment }\end{array}$ \\
\hline $\begin{array}{l}\text { 3D printing of human- } \\
\text { like vessels }\end{array}$ & $\begin{array}{l}\text { Vascular casting of vessel-like } \\
\text { networks that can be perfused and } \\
\text { lined with endothelial cells using, for } \\
\text { example, carbohydrate glass }{ }^{248} \text { or } \\
\text { biocompatible hydrogels }^{249}\end{array}$ & $\begin{array}{l}\text { Control of network geometry; can model } \\
\text { endothelial remodelling; cell-compatible } \\
\text { materials }\end{array}$ & Requires specific expertise and material \\
\hline $\begin{array}{l}\text { Chorioallantoic } \\
\text { membrane }\end{array}$ & $\begin{array}{l}\text { The chorioallantoic membrane from } \\
\text { the blood vasculature on the yolk } \\
\text { sac of a developing chick embryo is } \\
\text { used; transplantation of tissues onto } \\
\text { the chorioallantoic membrane or } \\
\text { intravenous injection of cancer cells } \\
\text { at around embryonic day } 12 \text { can be } \\
\text { used to study intravasation, CTCs } \\
\text { and extravasation }{ }^{194}\end{array}$ & $\begin{array}{l}\text { Fast assay; medium throughput; } \\
\text { low cost; amenable to live microscopy }\end{array}$ & $\begin{array}{l}\text { Embryonic vasculature might fail to } \\
\text { faithfully recapitulate metastatic } \\
\text { events in adult organisms; long-term } \\
\text { tracking is difficult owing to foreign } \\
\text { tissue rejection in late-stage embryos; } \\
\text { requires exogenous labelling of any } \\
\text { microenvironmental compartments }\end{array}$ \\
\hline Zebrafish models & $\begin{array}{l}\text { Cancer cells are introduced via } \\
\text { microinjection (for example, } \\
\text { intravenously or into the pericardium } \\
\text { or perivitelline space) at embryonic } \\
\text { stages from } 36 \mathrm{~h} \text { post-fertilization } \\
\text { onwards }^{14,153,186}\end{array}$ & $\begin{array}{l}\text { Fast assay; medium to high-throughput } \\
\text { assay with improved fidelity over } \\
\text { in vitro systems; low maintenance } \\
\text { costs; transparency at embryonic and } \\
\text { larval stages can be maintained to } \\
\text { facilitate imaging; growing toolbox of } \\
\text { transgenic lines to fluorescently label } \\
\text { the microenvironment for imaging; } \\
\text { amenable to pharmacological or } \\
\text { transient genetic manipulation }\end{array}$ & $\begin{array}{l}\text { Embryonic vasculature might fail to } \\
\text { faithfully recapitulate metastatic events } \\
\text { in adult organisms; lack of transparency } \\
\text { and potential foreign tissue rejection in } \\
\text { adult fish prevents long-term tracking; } \\
\text { different vascular structure, anatomy } \\
\text { and organization compared with } \\
\text { mammals or humans; zebrafish genome } \\
\text { duplication can hamper comparisons in } \\
\text { gene functions between zebrafish and } \\
\text { higher organisms }\end{array}$ \\
\hline Mouse models & $\begin{array}{l}\text { A very versatile platform; cancer cells } \\
\text { can be introduced via injection } \\
\text { (for example, intravenous, intrasplenic } \\
\text { or intracardiac) for short-term } \\
\text { metastasis assays, or genetically } \\
\text { engineered mouse models of } \\
\text { sporadic cancer formation can be } \\
\text { used to study autochthonous CTC } \\
\text { biology }\end{array}$ & $\begin{array}{l}\text { Allows assessment of CTC behaviour in } \\
\text { their native environment; genetically } \\
\text { engineered mouse models provide high- } \\
\text { fidelity insights into CTC biology; large } \\
\text { number of transgenic lines to label the } \\
\text { microenvironment; potential for surgical } \\
\text { interventions that are also performed in } \\
\text { human patients; amenable to short-term } \\
\text { and long-term pharmacological studies }\end{array}$ & $\begin{array}{l}\text { High maintenance and experimental } \\
\text { costs; induced or xenograft models } \\
\text { can be less relevant than spontaneous } \\
\text { disease models; intravital imaging } \\
\text { requires surgery or the insertion of } \\
\text { windows to access secondary sites } \\
\text { and/or organs; anaesthesia for imaging } \\
\text { might affect flow dynamics and fluid } \\
\text { mechanics }\end{array}$ \\
\hline $\begin{array}{l}\text { Patient CTC-derived } \\
\text { xenografts }\end{array}$ & $\begin{array}{l}\text { CTC isolation from whole-blood } \\
\text { samples from patients via enrichment } \\
\text { of epithelial cells and subsequent } \\
\text { transplantation into mice }{ }^{159,253-259} \text {; } \\
\text { however, it is becoming evident } \\
\text { that patient-derived CTCs can also } \\
\text { exhibit mesenchymal features, which } \\
\text { might require an optimization of } \\
\text { the isolation protocol. The potential } \\
\text { applications in studying patient- } \\
\text { specific responses to biomechanical } \\
\text { stress are largely unexplored }\end{array}$ & $\begin{array}{l}\text { Easily accessible via liquid biopsy at all } \\
\text { disease stages; xenografts maintain } \\
\text { similarity to original patient's disease and } \\
\text { treatment sensitivity and/or resistance; } \\
\text { longitudinal sampling is possible for } \\
\text { assessment of disease stages before and } \\
\text { after treatment or surgery; can be used } \\
\text { in the other models above with genetic } \\
\text { or pharmacological manipulation; allows } \\
\text { for personalized treatment approaches } \\
\text { and can be linked to clinical outcomes }\end{array}$ & $\begin{array}{l}\text { High maintenance and experimental } \\
\text { costs; strong involvement of ethical } \\
\text { regulations; rather low success rate } \\
\text { in patient CTC-derived xenograft } \\
\text { generation; clonality and/or } \\
\text { heterogeneity of samples; longitudinal } \\
\text { sampling might be limited by patient } \\
\text { tolerance, health status and/or disease } \\
\text { stage; currently, mostly limited to } \\
\text { introduction into immunodeficient } \\
\text { models }\end{array}$ \\
\hline Mathematical models & $\begin{array}{l}\text { Numerical modelling focuses } \\
\text { on the propagation, arrest and } \\
\text { formation of thrombus by CTCs. } \\
\text { Applications include modelling of: } \\
\text { real human vascularization and flow } \\
\text { propagation in } 3 \mathrm{D}^{102} \text {; the stiffness, } \\
\text { flowing properties and adhesion } \\
\text { of CTCs to the vessel wall }{ }^{104} \text {; the } \\
\text { margination properties of CTCs } \\
\text { with respect to erythrocytes } \\
\text { the haemodynamic behaviour of } \\
\text { CTC clusters (rotation and tumbling } \\
\text { during travelling) } \\
\text { thrombond and the } \\
\text { crowding }{ }^{107,260}\end{array}$ & $\begin{array}{l}\text { Versatility and tuneable parameters (for } \\
\text { example, flow rate, cell number, adhesive } \\
\text { and viscoelastic properties of CTCs); } \\
\text { predictive power that is unachievable } \\
\text { with experimental conditions }\end{array}$ & $\begin{array}{l}\text { Dependent on computing power and } \\
\text { time; 3D modelling remains complex, } \\
\text { cumbersome, time-consuming and } \\
\text { costly; difficult to integrate existing } \\
\text { models; absence of a specific platform } \\
\text { dedicated to the study of fluid } \\
\text { mechanics in cancer }\end{array}$ \\
\hline
\end{tabular}




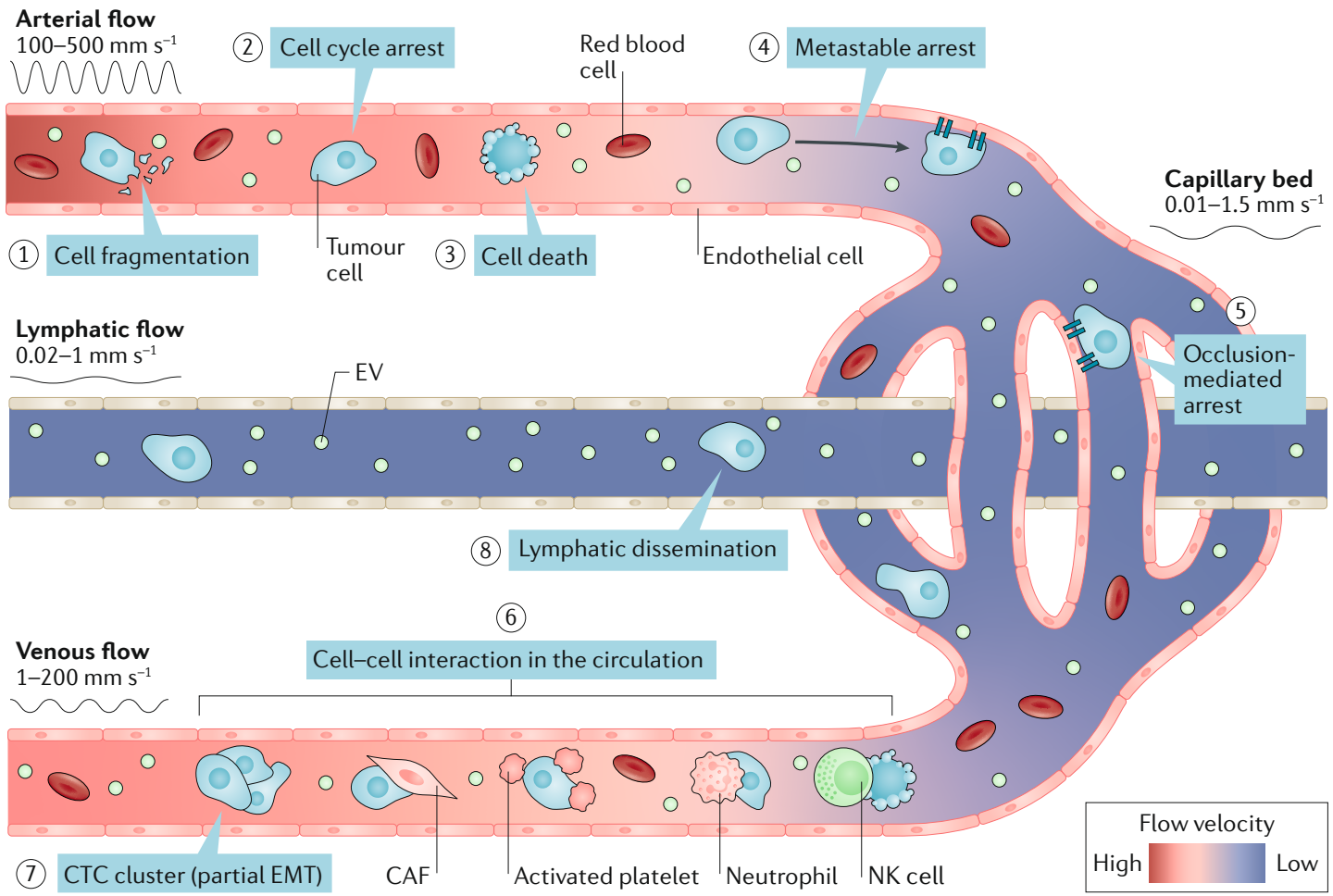

\section{Solid stress}

A stress exerted by the solid constituents of a tissue that accumulate within solid structural components (for example, extracellular matrix and tumour and stromal cells) during tumour growth.

Convective flow

A flow directed towards a gradient; in the case of a solid tumour, this is a pressure gradient.

Shear stress

A pressure that creates deformation when moving tangentially to a surface; for example, shear stress is generated when fluids flow over an endothelial surface.

\section{Margination}

A physical process that brings cells or vesicles close to the endothelial wall.

\section{Exomeres}

A type of extracellular vesicle that is characterized by small size ( $35 \mathrm{~nm})$ and the absence of a membrane; exomeres are enriched in metabolic enzymes and hypoxia-related, microtubule-related and coagulation proteins.

\section{Oncosomes}

A subtype of large membranederived extracellular vesicles (microvesicles) secreted by cancer cells that transfer oncogenic molecules to other cells.

Fig. 2 | CTCs in the blood and lymphatic intravascular environment. Circulating tumour cells (CTCs) experience several types of flow and interact with other CTCs or blood components that influence their metastatic potential. In arterial vessels, high flow velocities and shear stress lead to cell fragmentation (stage $\mathbf{1}$ ), cell cycle arrest (stage $\mathbf{2}$ ) and cell death (stage 3). Upon reaching organ capillary beds, CTCs will encounter lower flow velocities, promoting CTC arrest through active cell adhesion (fast-to-engage, low-energy metastable adhesions followed by slow-to-engage, high-energy stable adhesions) (stage 4) or through vessels with smaller diameter that favour occlusion-mediated arrest (stage $\mathbf{5}$ ). In venous vessels, lower flow velocities compared with arterial blood flow will favour the interaction of CTCs with other blood-borne cells (stage 6). CTCs can be targeted and destroyed by natural killer (NK) cells. CTCs have developed strategies to escape immune surveillance and favour their arrest, such as interaction with neutrophils, platelets or cancer-associated fibroblasts (CAFs) and also by travelling as clusters. Within clusters, CTCs with partial epithelial identity are observed, which will promote secondary organ colonization (stage 7). Low flow velocities and shear stress in the lymphatic system favour CTC survival, arrest, lymph node colonization and subsequent haematogenous dissemination (stage 8). EMT, epithelial-mesenchymal transition; EV, extracellular vesicle.

of EVs favours their margination close to the endothelium walls, similarly to synthetic nanoparticles ${ }^{73,74}$, enhancing their probability of being ingested by phagocytic cells, as recently observed in zebrafish embryos ${ }^{71}$. The size of EVs - which range from $35 \mathrm{~nm}$ for the recently described exomeres $^{75}$ to a few microns for oncosomes ${ }^{76}-$ might also affect their repartition in the blood flow and, ultimately, their organ distribution, as shown for gold nanoparticles in rats ${ }^{77}$. One could also speculate that the surface repertoire of EVs changes upon entering the bloodstream compared with that of extravascular EVs, leading to a change in their interaction dynamics with the microenvironment while in flow. In addition, EVs that are not rapidly taken up might be subjected to the high shear characteristic of arteries and could, therefore, potentially be destroyed, as shown for breast, ovarian and lung CTCs and for leukaemia cells in a microfluidics system ${ }^{78}$. In mice, tumour-derived EVs are also rapidly transported in lymphatics ${ }^{79}$, where they end up in metastasisfree lymph nodes and can be internalized by resident macrophages of the subcapsular sinus ${ }^{80,81}$. Similar observations have been reported for the dispersion of tumour antigens ${ }^{82}$ and circulating tumour DNA ${ }^{83}$.
Tumour-secreted factors can arrest in various metastasis-free organs, where they can create PMNs by locally altering the microenvironment prior to the arrival of tumour cells $s^{58,60,62,84}$. For instance, uptake of pancreatic tumour-derived EVs by Kupffer cells in mouse liver induced secretion of transforming growth factor- $\beta$ (TGF $\beta$ ), which led to changes in the ECM that promoted the recruitment of metastasis-supporting bone marrow-derived macrophages and granulocytes ${ }^{58}$. The complex molecular and cellular composition of PMNs can improve the efficiency of the subsequent colonization and survival of pioneer metastatic cells ${ }^{85}$. Remarkably, depending on their tumour origin, EVs can target specific cells and organs in mice ${ }^{60}$. For example, EVs derived from human breast cancer cells that metastasize primarily to the lung are mostly taken up by lung fibroblasts after intravenous injection in mice ${ }^{60}$. This organ specificity relies on the repertoire of integrins present on the surface of EVs ${ }^{60}$. However, the identity of the integrin ligands involved in this process, as well as the organ distribution of these ligands, is unknown. In addition, the general mechanism by which soluble and vesicular tumour-derived factors cross the endothelium 
to escape the circulation in specific organs is unclear. It could be linked to the capacity of tumour-derived EVs to induce endothelial permeability ${ }^{86-88}$; for example, in mouse models, melanoma-derived EVs were shown to promote vascular leakiness and educate prometastatic bone-marrow progenitor cells ${ }^{62}$ and multiple myeloid cells.

To date, the influence of flow forces on circulating tumour-derived factors has been very poorly described. However, observations from 2019 show that EVs circulate with reduced velocities in the proximity of the vessel walls - which is in line with the Hagen-Poiseuille equation, which states that the quadratic flow velocity profile is maximal at the luminal centre and minimal close to the vessel walls - and tend to arrest in regions of low blood flow in zebrafish ${ }^{71,89}$. As these regions are also the sites of efficient extravasation of CTCs ${ }^{14}$, it is tempting to speculate that the seeding of PMNs by EVs at specific organs and their subsequent colonization by CTCs occur in regions with similar shear flow profiles. This hypothesis can now be investigated using novel animal models in CTC research, such as zebrafish embryos, that enable tracking of EVs in the circulation ${ }^{71,89}$ (TABLE 2; see Supplementary Table 2), which opens new avenues for understanding the priming of metastatic niches at high spatiotemporal resolution.

\section{The intravascular journey of CTCs}

CTCs use various means to enter both the lymphatic and the vascular circulation, and their dissemination is tightly linked to fluid routes ${ }^{90}$ and arterial flow profiles ${ }^{12}$ (FICS 1a,2; TABLE 1). CTC dissemination can be analysed using a growing platform of animal models, experimental approaches and quantitative methods (TABLES 2,3; see Supplementary Table 2), and developments in 3D printing technologies have now enabled the design of human-like vessels at will, which are likely to provide unprecedented insights when applied to flowing properties of CTCs (TABLE 2).

Hagen-Poiseuille equation This equation describes the velocity in a laminar regime for a viscous fluid moving in a cylindrical tube as a quadratic distribution

Inertia

The extent to which cells and other material can maintain their motion against the flow.

Viscoelasticity This term defines a material that exhibits elastic and viscous behaviour when placed under stress.

Fluid-structure behaviour This behaviour occurs when the fluid deforms a physical structure, which will, in turn, modify the fluid flow.

Ramification

A process that occurs in the vasculature when a stem vessel is branching out into two smaller-sized vessels. haemodynamics that are comparable to those in human capillary beds, and the capillary diameter, blood velocity, Reynolds number and shear stress are very comparable between all models. As an example, we reported that the haemodynamic features of the zebrafish embryo resemble those of the human brain, demonstrating that the zebrafish embryo can be used as a model for tracking mechanisms of tumour metastasis when properly validated in a mammalian model ${ }^{14}$. In addition, our observations (using high-resolution electron microscopy) show that vascular remodelling is very similar between the mouse and zebrafish models, which suggests that similar mechanisms are used, independently of vascular basement membranes and ECM cross-linking, and could fully rely on the similar haemodynamic profiles observed.

During their journey in the blood vascular system, some CTCs will reach the arterial circulation, where flow shear stress and velocities are high (FIG. 2; TABLE 1). Here, the cells might undergo deformation due to high shear stress, causing fragmentation and death. In addition, a minor proportion of CTCs are known to circulate as clusters in mice and humans $\mathrm{s}^{53,94}$, and the trajectories of these clusters in the bloodstream have been shown to depend on their size and shape. For example, compact clusters (triangular or square-shaped) will flow in closer proximity to the endothelial barrier than linear clusters ${ }^{95,96}$. Such behaviour might increase their probability of engaging in adhesion with the endothelium, which can be further potentiated by the high density of adhesion proteins on $\mathrm{CTCs}^{97}$.

In regions where the vasculature undergoes ramification, flow remains pulsatile with low velocities and is predominantly driven by the viscous contribution (TABLE 1), as defined by fluid-structure modelling ${ }^{14,91}$. Thus, CTCs in flow are less exposed to shear stresses in these regions. Shear stress increases during intravascular arrest, which follows either active adhesion to the endothelium or occurs by mechanical trapping, as observed in mouse brain or lungs and rat livers ${ }^{13,98,99}$. During their journey in the circulation, tumour cells sense the shear stress ${ }^{100}$ of the flow that carries them and need to adapt their behaviour to arrest and extravasate. Mathematical models that mimic blood flow in capillaries and simulate erythrocytes have been developed ${ }^{101}$ and are likely to provide unprecedented insights into the intravascular behaviour of CTCs. Recent improvements in computational power now enable simulation of the blood flow in human pulmonary capillaries ${ }^{102}$, where complex erythrocyte deformation is integrated ${ }^{103}$. Such tuneable models can now be applied to flowing tumour cells, and have shown that CTCs need to adapt the stiffness of their cytoskeleton in a very specific manner in order to achieve full adhesion on the endothelial wall ${ }^{104}$. Similarly, margination properties of single CTCs versus clusters of CTCs can now be studied ${ }^{105}$. These models include single CTCs in the absence of erythrocytes ${ }^{104}$, complex flows populated with erythrocytes that subject CTCs to margination ${ }^{105,106}$ and thromboembolism of CTCs ${ }^{107}$.

Thus, CTCs are subjected to various haemodynamic forces while in transit, the strength of which strongly depend on the flow type, vascular region and organ. 
Table 3 | Quantitative methods to probe forces associated with metastatic extravasation

\begin{tabular}{|c|c|c|c|}
\hline Method & Application & Advantages & Disadvantages \\
\hline $\begin{array}{l}\text { Optical tweezers } \\
\text { for measuring } \\
\text { haemodynamic forces } \\
\text { in vivo }\end{array}$ & $\begin{array}{l}\text { In vivo measurement of forces on cells, } \\
\text { such as red blood cells }\end{array}$ & $\begin{array}{l}\text { Provides a direct readout of forces } \\
\text { experienced by cells in the circulation; } \\
\text { high fidelity; non-invasive }\end{array}$ & $\begin{array}{l}\text { Low throughput; high cost; } \\
\text { specialized skill set and equipment } \\
\text { required; limited depth in vivo; } \\
\text { requires intravital imaging } \\
\text { compatible animal models; limited } \\
\text { to forces } \sim 100 \mathrm{pN}\end{array}$ \\
\hline FRET biosensors & 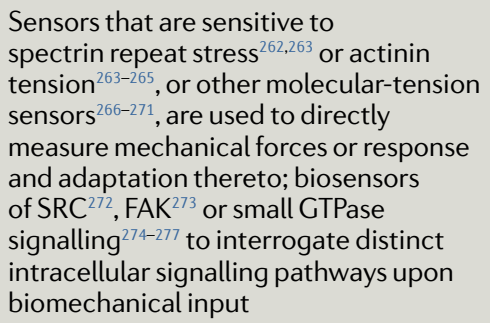 & $\begin{array}{l}\text { Single-cell and subcellular readouts } \\
\text { are achievable; reversibility of FRET } \\
\text { biosensors allows detection of dynamic } \\
\text { changes in biomechanical forces; } \\
\text { ongoing development to increase the } \\
\text { range of signalling pathways that can be } \\
\text { interrogated; compatible with in vitro } \\
\text { and in vivo readouts; longitudinal or } \\
\text { continuous mapping of force changes } \\
\text { and cellular responses }\end{array}$ & $\begin{array}{l}\text { Can require advanced imaging } \\
\text { and analysis setups; gauging of } \\
\text { fluorescence intensity/expression } \\
\text { levels is important; relatively low } \\
\text { dynamic range requires careful } \\
\text { calibration and experimental } \\
\text { controls }\end{array}$ \\
\hline $\begin{array}{l}\text { Measurement of } \\
\text { haemodynamic forces } \\
\text { using intravascular } \\
\text { beads }\end{array}$ & $\begin{array}{l}\text { Measurement of flow rate and } \\
\text { turbulence experienced by cells in } \\
\text { vessels by tracking injected fluorescent } \text { beads }^{14}\end{array}$ & $\begin{array}{l}\text { Enables visualization of flow rates } \\
\text { and turbulence; allows precise } \\
\text { measurements of flow velocities; } \\
\text { demonstrated in live animals }\end{array}$ & $\begin{array}{l}\text { Limited to regions where beads } \\
\text { can perfuse from the site of } \\
\text { injection; invasive method; requires } \\
\text { automated image analysis }\end{array}$ \\
\hline
\end{tabular}

FAK, focal adhesion kinase; FRET, Förster resonance energy transfer.

Further work is needed to determine whether the influence of flow profiles and vascular architecture on CTC behaviour differs between metastatic organ sites (FIG. 1 c; see Supplementary Table 1). However, CTCs have evolved mechanisms to resist and survive these intravascular stresses.

Impact of shear forces on CTCs. Metastatic tumour cells have been shown to disseminate rather efficiently from the primary lesion ${ }^{51}$. Interestingly, however, upon injection of tumour cells into the afferent vessel of metastatic organs, $<4 \%$ of injected cells efficiently form micrometastatic foci, although $\sim 80 \%$ of the cells are thought to stably arrest 1 day after injection ${ }^{108,109}$. In the context of murine brain metastasis, only $40-60 \%$ of the arrested cells sustain the ripping forces of the blood flow and extravasate ${ }^{99}$, which suggests that the inefficiency of the first metastatic steps is related to an intravascular pre-extravasation event. Further deleterious effects for metastasis are driven by the immune system ${ }^{110}$ or by microenvironmental niches that restrain tumour growth or induce dormancy ${ }^{90,108,109}$. Work in mouse models of breast cancer metastasis has shown that some CTCs develop organ-specific survival strategies against such restraints (for example, upregulation of antioxidant programmes in the case of lung metastasis) to successfully seed secondary sites ${ }^{111}$.

CTCs suffer from shear stress and collisions that can induce cell cycle arrest (demonstrated for a shear stress of $\left.12 \mathrm{Dyn} \mathrm{cm}^{-2}\right)^{112}$ (FIG. 2) as well as physical damage and necrosis ${ }^{113}$ (caused by shear values of $\approx 6{\text { Dyn } \mathrm{cm}^{-2}}^{-2}$ REF. $^{114}$ ) and gradually increasing with laminar shear stress ${ }^{115}$ ). Moreover, programmed cell death leading to apoptosis is induced by shear stress in vitro with shear values of only 2 Dyn $\mathrm{cm}^{-2}\left(\right.$ REF. $\left.^{116}\right)$. Such low shear stress may reduce the metastatic efficiency. Interestingly, an oscillatory shear stress of $\approx 4 \mathrm{Dyn} \mathrm{cm}^{-2}$ had no effect on the death of human tumour cells, suggesting that the type (and duration) of flow is equally important ${ }^{115}$; of note, this remains largely underexplored and seems to be highly dependent on the cell type. Intriguingly, some CTCs can survive

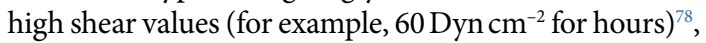
but whether they consequently develop increased metastatic capacities remains to be explored. CTCs of various origins have been shown to develop survival strategies and, when exposed to short but intense and disruptive shear stress pulses in vitro, can repair their plasma membrane $^{117}$ through a calcium-dependent vesicle fusion mechanism, which could be similar to what has been described in starfish oocyte ${ }^{118}$. The intravascular survival of CTCs also relies on the nucleus resisting shear stress, which can be mediated by lamin $\mathrm{A}$ and $\mathrm{C}^{114,119}$ or by the small GTPase RAC1 under the control of its guanine nucleotide exchange factor, $\mathrm{T}$ lymphoma invasion and metastasis-inducing protein 2 (TIAM2: also known as $\mathrm{STEF})^{120}$. Interestingly, a comparison of primary human breast cancer cells and CTCs suggested that flowmediated DNA damage and the subsequent acquisition of mutations in surviving CTCs is linked to increased resistance to chemotherapy and metastatic seeding ${ }^{121}$.

Shear forces can even initiate signalling pathways that drive resistance mechanisms. For example, CTCs from patients with breast, prostate or lung cancer have increased expression of $\beta$-globin, which protects them from the intracellular accumulation of reactive oxygen species induced by shear stress ${ }^{122}$. Similarly, flow-dependent activation of mitochondrial superoxide dismutase (MnSOD; also known as SOD2) decreases levels of reactive oxygen species $^{123}$. In addition, reversible metabolic adaptations, such as activation of the folate pathway, allow CTCs to 
withstand oxidative stress, readily adjust to new environments and survive in transit, as described in the context of human melanoma xenografts ${ }^{124}$. CTCs also endure anoikis ${ }^{125}$, which triggers apoptosis in tumour cells upon loss of cell attachment to ECM components. Although the contribution of flow forces to anoikis has been mostly studied using cells in suspension and, therefore, remains to be fully demonstrated, several molecular mechanisms have been identified. For example, cell adhesion proteins such as integrins ${ }^{126}$ efficiently block anoikis, as demonstrated in mouse models of metastasis ${ }^{127}$. Integrin signalling can suppress anoikis by internalizing ECM fragments (and their own activated integrin subunits) into the endosomal compartment ${ }^{128}$. In addition, anoikis can be blocked upstream of integrin signalling and independently from ECM binding by zinc finger protein 304 $(\mathrm{ZNF} 304)^{129}$. Similarly, using tumour cells in suspension and metastasis assays in mice in the context of intestinal carcinoma $^{130}$ and hepatocellular carcinoma ${ }^{131}$, expression of the neurotrophic receptor tropomyosin-related kinase B (TRKB; also known as NTRK2) or binding of midkine (also known as NEGF2) to its receptor were shown to activate PI3K signalling, which blocks anoikis and increases metastasis.

Shear forces also activate other transcriptional programmes in CTCs. For instance, using microfluidic approaches (TABLE 2; see Supplementary Table 2), lymphatic-like (but not vascular-like) fluid shear stress was shown to promote cell migration and motility in a Yes-associated protein 1 (YAP1)-dependent manner ${ }^{132}$. Such shear stress was also shown to support cell division in a transcriptional co-activator with PDZ-binding motif (TAZ)-dependent manner ${ }^{133}$, suggesting that CTCs can orchestrate various signalling pathways in response to shear forces in vitro. Whether CTCs behave similarly in vivo remains to be determined.

Metastatic progression is often linked to epithelialmesenchymal transition (EMT) at the primary tumour ${ }^{134}$ and mesenchymal-epithelial transition upon arrival at the secondary site ${ }^{135}$. Interestingly, shear stress has been shown to trigger EMT in the context of several cancers in vitro ${ }^{136}$. However, CTCs tend to be very plastic and CTCs from patients with breast cancer, for instance, express both epithelial and mesenchymal markers ${ }^{53,137}$. Indeed, CTCs from breast or pancreatic cancer readily switch between epithelial and mesenchymal states, further favouring their survival as well as their invasive and metastatic potential in a diverse range of environments ${ }^{138-141}$. How blood flow influences mesenchymalepithelial transition and/or EMT programmes, tumour cell plasticity and metastatic potential remains to be elucidated. Shear stress was shown to induce EMT in CTCs and concomitantly promote stemness with high tumour-initiating potential ${ }^{142}$. This subpopulation of cells is characterized by decreased F-actin assembly and stiffness as well as delayed adhesion, which together seem to promote cell survival ${ }^{143}$.

A state of least energy unti

more external energy is added to the system; this state seems to be stable, although it is, in theory, unstable and capable of changing to a more stable state.
Cell-cell interactions in the blood. When transported in the bloodstream, CTCs are likely to interact with each other within the bloodstream or collide with blood components and the vasculature walls. CTCs are not equipped with the strategies that allow white blood cells ${ }^{117,144}$ and red blood cells ${ }^{145,146}$, for example, to resist detrimental shear forces and are, therefore, unlikely to successfully form a metastatic colony. For survival, CTCs have developed methods to interact with blood components or exploit existing shear forces (FIG. 2).

Clustering of CTCs - which can occur at intravasation, in transit or at arrest sites ${ }^{147}-$ increases their resistance to detrimental shear forces as well as assault by the immune system ${ }^{53}$ (for example, by natural killer cells $^{148}$ ) (FIG. 2). CTC clusters can be polyclonal, with many cells undergoing only partial EMT while retaining some epithelial features ${ }^{137}$, including cell-cell adhesion mechanisms ${ }^{147}$. Interestingly, members of the cadherin superfamily and plakoglobin were found to be expressed in CTC clusters from mouse and human breast can$\operatorname{cers}^{53,149}$, thereby enabling stable cell-cell adhesion while maintaining proliferative potential. CD44 was also shown to mediate homophilic interaction between CTCs from patients with breast cancer ${ }^{150}$. In addition to mediating cell-cell adhesion in CTC clusters, which is instrumental for their stemness properties and resistance to shear forces and anoikis, CD44 is a cancer stem cell marker ${ }^{151}$ and is characteristic of tumour-initiating potential ${ }^{152}$.

In addition to providing pro-survival properties, mathematical modelling suggests that travelling in clusters increases the drag force and decreases the speed at which CTC clusters circulate, thereby favouring interactions with endothelial cells and the intravascular arrest of CTCs ${ }^{95,96}$. Clusters are more likely to physically lodge in microvessels at distant sites before seeding metastatic colonies, as inferred from experiments in mice ${ }^{53}$. Of note, in the context of metastasis in the rat liver, this metastable arrest has been described as independent of integrinmediated stable adhesion ${ }^{98}$ (FIG. 2). As mechanical constraints imposed by vessel architecture and size contribute to the arrest of CTCs ${ }^{99}$, clusters of CTCs should be rapidly trapped and cleared from the circulation before reaching distant organs. Indeed, the half-life of mammary carcinoma CTC clusters in the circulation was lower than that of single CTCs in mice ${ }^{53}$. Surprisingly, however, clusters of CTCs are also capable of squeezing through capillary-sized vessels in vitro (in microfluidic devices) or in vivo (in zebrafish) ${ }^{153}$ (FIG. 3) and can resist attack from various blood-borne immune cells ${ }^{125}$. Furthermore, clusters of CTCs have been shown to reduce their hydrodynamic resistance by forming singlefile structures that rely on intercellular adhesive interactions ${ }^{153}$. Additional work is needed to better understand whether the increased metastatic potency of CTC clusters can be explained by an increased propensity to arrest and extravasate.

In addition to circulating as clusters, CTCs can directly interact with other cell types, such as cancerassociated fibroblasts ${ }^{154}$, when in transit. These cells are derived from the stroma of the primary tumour and can accompany CTCs to their secondary destination ${ }^{155,156}$. The interactions between CTCs and stromal cells are hypothesized to modify the intravascular behaviour of CTCs and favour metastasis ${ }^{154,155}$.

In the circulation, CTCs are no longer protected by the primary tumour microenvironment ${ }^{147}$ and, 


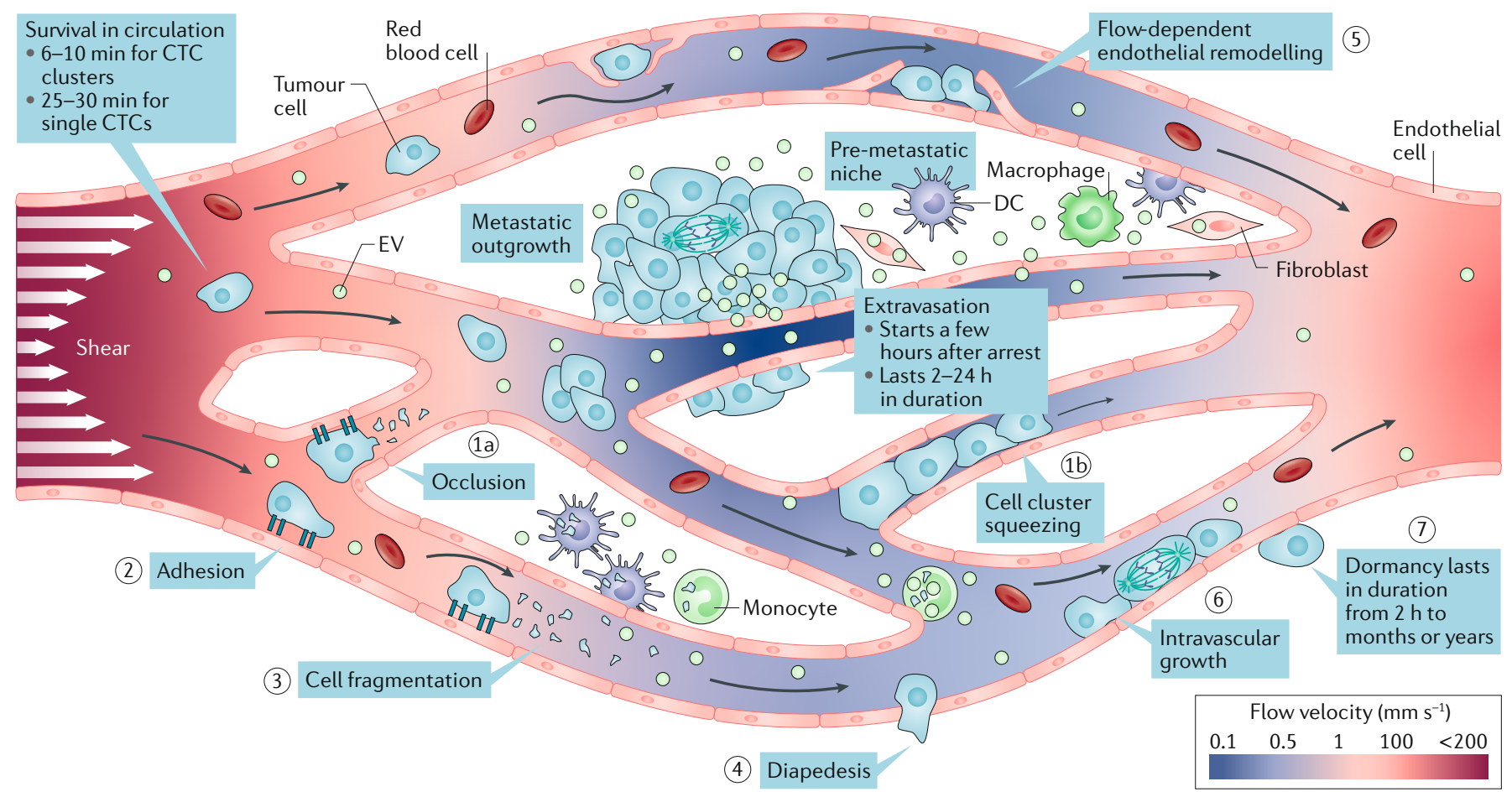

Fig. 3 | Tumour cell extravasation is a flow-dependent process. Extravasation of circulating tumour cells (CTCs) occurs mostly in capillary beds, where cells are able to arrest. This can occur either by physical occlusion (stage 1a) ${ }^{99,196}$, despite the obvious potential for deformation due to cell cluster squeezing (stage $\mathbf{1 b})^{153}$, or by active and stable adhesion with endothelial cells (stage 2) ${ }^{168,184,187,189}$. CTCs that are stopped in the circulation will suffer from increased levels of shear stress, which can lead to cell fragmentation (stage $\mathbf{3}^{13}$ and the subsequent modification of vessel permeability. Subsequently, several extravasation scenarios are plausible. Cancer cells could undergo diapedesis (stage 4), be extruded through flow-dependent endothelial remodelling (stage 5) ) $^{14}$ or grow intravascularly to form intraluminal metastases (stage 6) ${ }^{173}$. Following extravasation, some cancer cells will remain dormant for years to decades (stage 7) ${ }^{199}$. DC, dendritic cell; EV, extracellular vesicle.

therefore, are more exposed to immune cells (FIG. 2), including circulating $\mathrm{T}$ lymphocytes and natural killer cells ${ }^{157}$. Here, CTCs can interact with and co-opt other circulating cell types to evade the immune system and drive metastasis. In mice, CTCs cluster with neutrophils in the bloodstream ${ }^{158,159}$ and exploit these immune cells to bind to and arrest on vessel endothelial walls while resisting shear stress ${ }^{158,160}$. These heterotypic interactions between CTCs, neutrophils and the endothelium are, at least in vitro ${ }^{161}$, mediated by a repertoire of cell adhesion proteins, including integrins, cadherins and cell-surface glycoproteins, and might provide another druggable axis for targeting CTC vulnerabilities.

Furthermore, CTCs have been shown to recruit and activate platelets ${ }^{162}$ (which have long been implicated in cancer metastasis ${ }^{163}$ ), the latter step also being dependent on blood flow ${ }^{164}$. Indeed, thrombocytopenia, which decreases the CTC-platelet interaction, correlates with reduced metastatic potency of CTCs ${ }^{163}$. Platelets are thought to shield CTCs against mechanical stress and immunosuppressive factors ${ }^{165,166}$ and further enable the binding of tumour cells to the endothelial wall through their natural ability to interact with P-selectin glycoprotein ligand 1 (PSGL1) or platelet endothelial adhesion molecule 1 (PECAM1) on endothelial cells $^{167,168}$. Moreover, platelets can protect CTCs against anoikis in a YAP1-dependent manner in vitro and promote metastasis in mice ${ }^{169}$. In addition to their various pro-metastatic properties, platelets and specific platelet receptors were shown to have anti-metastatic effects in murine models ${ }^{170,171}$, raising questions regarding their exact contribution to metastatic onset or indicating a timing-dependent or context-dependent role for platelets in the metastatic cascade. Although the contribution of platelets to the metastatic potential of CTCs is unquestionable, additional work is needed to clarify how platelets behave under shear conditions with respect to CTCs and CTC survival.

\section{Intravascular arrest and extravasation}

In addition to intravasation and survival in the circulation, successful intravascular arrest and extravasation is also dictated by flow-mediated forces before metastatic outgrowth, and CTCs use similar ancillary mechanisms to co-opt native cell types or fluid flow to facilitate colonization of secondary sites.

Fluid forces in intravascular CTC arrest. Metastatic onset depends on a plethora of molecular programmes ${ }^{172}$ but also relies on the successful intravascular arrest (or intravascular growth) ${ }^{173}$ of CTCs before metastatic extravasation. Two main behaviours, which are not mutually exclusive, are responsible for the intravascular arrest of single or clustered CTCs that precedes
Thrombocytopenia
A condition characterized by low platelet count. 


\section{Bell's model}

A statistical model taking into account the chemical rates of formation and dissociation

between ligands and receptors as well as the statistical

distribution of these ligandreceptor pairs on two cell

surfaces when external forces are applied

\section{Diapedesis}

The transmigration process by which circulating cells exit the bloodstream using either the transcellular (through endothelial cells) or the paracellular (between endothelial cells through cell-cell junctions) route.

Catch bonds Receptor-ligand interactions, the strength and lifetime of which increases under applied force. metastatic outgrowth - physical occlusion in microvessels or capillaries, as observed, for instance, on intravital imaging of human lung adenocarcinoma or melanoma CTCs in mouse brains ${ }^{99}$, and active adhesion of CTCs to vessel walls, as described in various in vitro and in vivo models ${ }^{14,174,175}$. In some instances (for example, in the rat liver), physical occlusion cannot fully account for the efficient extravasation, suggesting that active adhesion between CTCs and the vascular wall upon the physical trapping of CTCs is still required for extravasation and successful metastasis ${ }^{98}$ (FIG. 3).

From a biophysical standpoint, Bell's model provides an optimal framework for describing the interaction and adhesion between CTCs and the endothelium under flow $^{176,177}$. Such a model takes into account the external fluid force as well as the homogeneously distributed adhesion receptors that bind to the vessel wall (that is, the number of physical contacts and the adhesion strength of contact between the CTC and the endothelial cell). When chemical bonds such as ligand-receptor interactions are subjected to external forces (including fluid flow), their adhesion energy has to overcome the energy of the fluid that is displaced. This model has been widely used to dissect the molecular machineries at play during leukocyte attachment to vessel walls ${ }^{178}$, but the physicochemical requirements for CTC attachment that allow adhesion to overcome shear forces remain largely unclear.

Interestingly, in vitro studies have suggested that CTCs hijack the arrest and transmigration strategies used by leukocytes during rolling ${ }^{179}$ and diapedesis. Rolling allows leukocytes to engage adhesion molecules on the surface of vascular endothelial cells and, therefore, reduce their velocity in the flow. Microfluidics studies have shown that the rolling of CTCs is mediated by the interaction between selectins at the endothelial surface and various glycoproteins at the surface of CTCs of different origin ${ }^{180}$. In the case of leukocyte rolling, receptor activation and flow-mediated endothelial stiffening ${ }^{181}$ (owing to flow pushing on the arrested cells and pulling on adhesions) will then trigger endothelial cell-cell junction opening and favour diapedesis ${ }^{182}$. CTCs might exploit similar flow-dependent mechanisms, whereby they would adhere to the vessel walls by first being slowed down by weak adhesion forces with fast activation rates. This initial transient interaction can provide time to activate and engage receptors with slower activation rates but higher adhesion forces ${ }^{5,178,183}$. Recent work by our group has dissected the molecular machineries at play during the arrest of mouse mammary CTCs in vitro and in vivo and identified CD44 and $\beta 1$ integrin as key mediators of CTC arrest by counteracting the shear forces that detach the CTCs from the endothelium (as described by Bell's model) ${ }^{14,184}$. Such stable intravascular arrest markedly underpins successful metastatic extravasation ${ }^{184}$. Whether the forces in the blood favour reinforcement of the adhesion via CTC rolling or catch bonds remains to be studied ${ }^{185}$. The emergence of new quantitative tools to probe forces during CTC extravasation (TABLES 2,3; see Supplementary Table 2) now enables documentation of the flow-dependent intravascular arrest of CTCs at high spatiotemporal resolution $^{14,186}$. In addition, intravascular arrest, whether through physical trapping or active adhesion, is likely to be one of the most deleterious steps for CTCs - cells must resist shear stress while simultaneously establishing a stable engagement with the endothelium ${ }^{168,187}$. Upon adhesion, CTCs have a finite adhesion force (that is, the force strength of the engaged adhesion receptor) to the vessel wall. Thus, CTCs are engaged in a 'tug of war' between their limited adhesion strength and the force that the flow exerts on them, with two possible outcomes. If the CTC adhesion force is weaker than the shear stress, the CTC cannot adhere or is washed away. However, if the CTC adhesion force is equal to or stronger than the shear stress, the cells can arrest $\mathrm{t}^{14,184}$. In the context of intravascular injection of mammary carcinoma cells in zebrafish and mouse models of brain metastasis, a shear stress of 5-7 Dyn $\mathrm{cm}^{-2}$ favoured CTC arrest and, therefore, colonization ${ }^{14}$. Further work will be required to investigate whether such values are valid in the context of other organs or cell types.

In addition to influencing the ability of CTCs to arrest in certain vascular regions, fluid forces influence the fate of arrested CTCs. Indeed, shear forces challenge their survival at potential colonization sites and are likely to detach already-adhered CTCs from the endothelium ${ }^{14}$. As arrested CTCs experience higher shear forces than CTCs that have not adhered to the endothelium ${ }^{188}$, they must develop mechanisms of adhesion to efficiently resist such forces for successful extravasation ${ }^{14,184,186}$. Intravital imaging of arrested tumour cells in mouse models of brain metastasis revealed that high shear forces can be deleterious to arrested CTCs ${ }^{99}$. In addition, intravital imaging of melanoma cells in mouse lungs revealed that high shear forces can fragment arrested tumour cells ${ }^{13}$, which will eventually recruit phagocytic cells that can influence metastatic onset ${ }^{189}$. Interestingly, arrested CTCs face mechanical constraints comparable to those influencing tumour cell invasion at the primary tumour and, therefore, could be potentially exposed to the extensively studied cell-deformation-related events that occur in confined spaces ${ }^{190}$. Such stresses, which alter nuclear morphology $y^{191-193}$ and influence gene expression and cell survival in vitro (TABLE 1), have been modelled using microfluidic approaches and could be a result of shear forces at sites of intravascular arrest (TABLE 2; see Supplementary Table 2). However, whether they are at play during the intravascular arrest of CTCs, especially in vivo, remains unclear.

Fluid forces in CTC extravasation. Mechanistically, CTC extravasation is thought to mirror immune cell extravasation $^{181}$, but the contribution of shear forces to this step remains elusive. Whether blood flow forces modulate this step in vivo remains unknown. The development and validation of new animal models and imaging techniques will enable assessment of the contribution of flow forces to metastatic extravasation in greater detail (TABLE 3). For example, in vivo chorioallantoic membrane assays (TABLE 2; see Supplementary Table 2) show that cancer cell extravasation can involve cell protrusion (invadopodia), actomyosin contractility and secretion of matrix metalloproteinases ${ }^{194,195}$. In addition, advances in intravital imaging models and technologies 
Cytoplasts

Nucleus-free portions of cells

that are released from arrested

circulating tumour cells when

facing high shear forces.

Necroptosis

A process that induces cell

death through controlled

necrosis.
(TABLES 2,3; see Supplementary Table 2) now enable the precise study of the signalling dynamics that occur during cancer cell extravasation (FIG. 3), as exemplified by the activation of SRC kinase upon the arrival of metastatic pioneer cells in the liver in a murine model of pancreatic cancer ${ }^{196}$.

Data suggest that shear forces can stimulate nontumour components, such as platelets (observed with shear values of 7-8 Dyn $\left.\mathrm{cm}^{-2}\right)^{164}$ and endothelial cells (observed with shear values of 5-7 $\left.\mathrm{Dyn} \mathrm{cm}^{-2}\right)^{14}$. Indeed, permissive flow velocities (corresponding to $\sim 500 \mu \mathrm{m} \mathrm{s}^{-1}$ ) allow endothelial cells to migrate intraluminally in the presence of arrested CTCs in zebrafish or mice ${ }^{14,197}$ (FIG. 3). The endothelial cells progressively enwrap arrested CTCs and preserve or re-establish normal perfusion while expelling metastatic CTCs that have survived detrimental shear forces out of the vessel ${ }^{14}$. Interestingly, similar flowdependent mechanisms have been described in mice for removing blood clots from blood vessels ${ }^{198}$. Although the influence of shear forces on tumour cell dormancy has never been studied, it would be interesting in the future to determine whether perivascular niches ${ }^{199}$ that provide a chemo-protective environment for dormant tumour cells ${ }^{200}$ originate from cells that have extravasated through flow-dependent endothelial remodelling ${ }^{14}$ and whether they could be localized and, therefore, identified on the basis of flow profiles. In the context of lung metastasis, shear forces rip fragments off arrested CTCs (FIG. 3) and promote competition between different immune cell populations that ingest the resulting cytoplasts, thereby creating a PMN by favouring the recruitment of neutrophils, monocytes, macrophages and rare lung-resident dendritic cells ${ }^{13}$. The resultant cytoplasts are ingested by several immune cell types that are recruited to that site and modulate the extravasation of other CTCs. Alternative scenarios that require coordination between endothelial cells and CTCs can drive metastatic extravasation. For example, extravasation of tumour cells has been described to occur via endothelial cell apoptosis in vitro ${ }^{201}$ and endothelial necroptosis in a mouse model of lung metastasis ${ }^{202}$. In addition, tumour cells can proliferate intraluminally to create massive emboli that are surrounded by endothelial cells but that stay bound to the normal vessels ${ }^{173,197}$ (FIG. 3).

In summary, in addition to influencing the fate of CTCs, fluid forces are capable of stimulating stromal components that are likely to shape metastatic success.

\section{Fluid-targeting strategies}

Advances in single-cell molecular analysis have enabled the identification of strong intracellular heterogeneity within CTC populations ${ }^{203}$. Although such heterogeneity is caused by genetic instability or cellular plasticity, it is very likely that individual cells or clusters of CTCs differ between tumour types and patients and might, therefore, respond very differently to not only treatment but also fluid flows. Many pharmacological agents that target blood flow and blood flow mechanics have been approved for clinical use in, for example, the treatment of cardiovascular diseases. Such drugs, including anticoagulants, $\beta$-blockers or angiotensin-converting enzyme inhibitors, might also influence cancer metastasis.
For example, the anticoagulant hirudin was shown to profoundly reduce CTC numbers and metastasis in the $4 \mathrm{~T} 1$ mouse model of breast cancer, potentially by disrupting the interaction between platelets and cancer cells $^{204}$. Similarly, local pro-coagulative environments have been detected within the blood vessel lumen at primary and secondary tumour sites, where they might facilitate intravasation and extravasation, and heparins targeting these environments were shown to reduce metastasis in preclinical models ${ }^{205,206}$.

In mouse models of breast cancer, chronic stressinduced $\beta$-adrenergic signalling, which increases the heart rate and alters blood pressure, has also been shown to promote metastasis while increasing blood and lymphatic vessel density in the primary tumour and elevating the lymph flow rate in draining collectors; these mechanisms were all successfully targeted using the $\beta$-blocker propranolol ${ }^{207,208}$. As $\beta$-adrenergic signalling was also shown to increase cancer cell stiffness during invasion $^{209}$, it is interesting to speculate about whether $\beta$-adrenergic signalling can also protect CTCs from deformation and immune assault in the circulation. Interestingly, in patients with breast cancer, short-term intervention using a combination of the $\beta$-blocker propranolol and the cyclooxygenase 2 (COX2) inhibitor etodolac during the perioperative period was sufficient to reduce pro-invasive and pro-inflammatory gene signatures in the tumour tissue $\mathrm{e}^{210}$. Whether this transient intervention at this crucial perioperative period, when patients experience high levels of stress, can also influence CTC abundance and metastasis in the long term should be assessed in future preclinical and clinical studies.

Lastly, retrospective studies have indicated an anticancer and anti-metastatic benefit for drugs targeting the renin-angiotensin system, which are commonly used to reduce hypertension and arterial blood pressure ${ }^{211,212}$ (reviewed elsewhere ${ }^{213}$ ). Interestingly, the reninangiotensin system inhibitor losartan was shown to provide not only anti-hypertensive but also anti-fibrotic benefits by decreasing ECM levels, thereby reducing physical stress, decompressing blood vessels and improving interstitial flow and the delivery and efficacy of therapeutics in the tumour ${ }^{214,215}$ (BOX 1). Similarly, we have previously demonstrated that transient intervention with the vasodilator fasudil in a preclinical model of pancreatic cancer decreased both fibrosis and metastasis while increasing vascularization and improving the efficacy of chemotherapy ${ }^{216}$. Furthermore, targeting the ECM component hyaluronic acid using pegvorhyaluronidase alfa (PEGPH20), a pegylated recombinant human hyaluronidase enzyme, was shown to normalize IFP and improve vascularization and chemotherapy efficacy ${ }^{33}$.

As intravascular arrest, which is dependent on precisely balanced force interactions between CTCs and the endothelium, is a crucial step in metastasis, it might also be particularly amenable to therapeutic targeting. For example, fluid-targeting agents, such as the $\beta$-blockers or renin-angiotensin system inhibitors, could be used to manipulate vascular profiles in order to detach alreadyadhered CTCs from the endothelium. In addition, anticoagulants might serve to eradicate local pro-metastatic 
Endothelial remodelling

A process that represents the ability of endothelial cells to sense and respond to stimuli (such as fluid flow, shear stress and trafficking of immune cells] by remodelling their contact adhesion to move towards specific reorganization, leading to flow homeostasis.

\section{Liquid biopsy}

The collection of non-solid tissues, such as blood, and screening it for disease-related parameters, such as circulating tumour cells. In contrast to biopsy of solid internal tissues, liquid biopsy is minimally invasive and suited for repeated assessment in the same patient. environments within the vessel lumen to impede initial CTC arrest, while also interfering with the interaction between CTCs and platelets in transit, thereby re-exposing CTCs to shear stress and collision.

As extensive clinical data from large prospective patient cohorts using fluid-targeting agents are still sparse, further research will be required to determine the efficacy, mechanism of action and optimal timing for intervention and to identify patient subgroups that will likely benefit from these treatments.

\section{Conclusions}

The fate of tumour cells in transit and of tumourassociated factors during metastasis is established to be tightly controlled by bodily fluids and their associated mechanics. However, multiple challenges remain in fully elucidating the involvement and targeting of fluid mechanics in metastasis.

Fluid displacement within tumours and the underlying forces of the fluids are very likely to increase the dissemination of detectable tumour-associated factors that might have strong prognostic potential. Although the influence of these forces on drug delivery has been studied extensively ${ }^{22}$ (BOX 1), we believe that additional investigation is required to further understand how they promote tumour dissemination. Further work is also needed to address whether shear forces and fluid mechanics modulate the secretion and dissemination of tumour-secreted factors and, therefore, the formation and location of PMNs and metastatic foci from distinct tumours. It is likely that flow routes and shear forces influence the arrest sites of soluble molecules and EVs alike, as they have also been shown to affect the internalization of small-scale synthetic nanoparticles by endothelial cells in vitro ${ }^{217,218}$. In addition, fluid shear stress improves the efficacy of reactive oxygen species-generating anticancer compounds, such as doxorubicin or cisplatin, which might provide an opportunity to exploit fluid mechanics to drive the targeted apoptosis of CTCs ${ }^{113}$. Organotropism and the tumour-type distribution of secondary tumours (as well as other molecular factors) could result, for example, from distinct flow profiles and vessel architecture within and between organs. The combination of animal models with intravital imaging technologies at unprecedented spatiotemporal resolution ${ }^{185}$ is likely to facilitate a major leap towards the understanding of PMN priming. Although the clinical relevance of the metastatic detour from lymph nodes to distant organs remains to be determined, it will certainly influence management decisions in patients. As myeloid populations can sense tumourderived material that is either transported or shed by fluid flows ${ }^{71}$, shear forces might tune such immune recognition of flowing tumour cells. An improved understanding of how immune cell populations compete and are recruited at metastatic sites by fluid-borne material could lead to the design of refined anti-metastatic immunotherapeutic approaches. Similarly, strategies aiming to reduce flowmediated pro-metastatic endothelial remodelling should be explored in the future. Anti-metastatic preventive interventions could also be explored based on metastasis predilection sites, which would target regions with permissive flow profiles. Finally, whether clusters of CTCs are better equipped than individual CTCs to co-opt other blood components or to adapt to shear forces during transit and to vascular constraints at metastatic sites remains to be demonstrated. Improvements in the sensitivity of liquid biopsy analysis now enables the probing of minimal residual disease in cases where metastatic foci or residual tumour cells (after therapy) cannot be detected using conventional imaging techniques ${ }^{66}$. If combined with the specific detection of fluid-dependent biomarkers within CTCs, CTC clusters or the interaction of CTCs with relevant blood components (platelets or neutrophils), these methods are likely to boost the predictive and monitoring power of liquid biopsies.

Thus, it is increasingly clear that metastasis should be studied not only from biochemical and genetic perspectives but also from a biomechanical angle that reveals how flow-associated forces influence metastasis. Such efforts could improve our understanding of cancer metastasis while providing new methods to improve its detection and eradication. Further work is, therefore, needed to determine whether fluid mechanics can be used to improve the targeting of anti-metastatic strategies.

Published online: 28 November 2019
1. Massagué, J. \& Obenauf, A. C. Metastatic colonization by circulating tumour cells. Nature 529, 298-306 (2016).

2. Martin, J. D., Seano, G. \& Jain, R. K. Normalizing function of tumor vessels: progress, opportunities, and challenges. Annu. Rev. Physiol 81, 505-534 (2019).

3. Mohammadi, H. \& Sahai, E. Mechanisms and impact of altered tumour mechanics. Nat. Cell Biol. 20, 766 (2018).

4. Northey, J. J., Przybyla, L. \& Weaver, V. M Tissue force programs cell fate and tumor aggression. Cancer Discov. 7, 1224-1237 (2017).

5. Wirtz, D., Konstantopoulos, K. \& Searson, P. C. The physics of cancer: the role of physical interactions and mechanical forces in metastasis. Nat. Rev. Cancer 11, 512-522 (2011).

This review provides one of the first important discussions of how mechanical forces control interactions between cancer cells and their microenvironment, including blood flow, and how such forces are essential to the metastatic process.

6. Koumoutsakos, P., Pivkin, I. \& Milde, F. The fluid mechanics of cancer and its therapy. Annu. Rev. Fluid Mech. 45, 325-355 (2013).
7. Swartz, M. A. \& Lund, A. W. Lymphatic and interstitial flow in the tumour microenvironment: linking mechanobiology with immunity. Nat. Rev. Cancer 12, 210-219 (2012)

8. Peinado, $\mathrm{H}$. et al. Pre-metastatic niches: organ-specific homes for metastases. Nat. Rev. Cancer 17, 302-317 (2017).

9. Brown, M. et al. Lymph node blood vessels provide exit routes for metastatic tumor cell dissemination in mice. Science 359, 1408-1411 (2018).

This paper shows that tumour cells experimentally delivered to lymph nodes can efficiently disseminate by invading local blood vessels; lymph node blood vessels are, therefore, also used by cancer cells for efficient dissemination to distant organ

10. Naxerova, K. et al. Origins of lymphatic and distant metastases in human colorectal cancer. Science 357, 55-60 (2017).

11. Pereira, E. R. et al. Lymph node metastases can invade local blood vessels, exit the node, and colonize distant organs in mice. Science 359, 1403-1407 (2018).

This paper uses photoconversion of tumour cells to track the fate of metastatic cells located in the lymph nodes, demonstrating that such cells efficiently leave lymph nodes via local blood vessels to seed distant organs.

12. Weiss, L., Bronk, J., Pickren, J. W. \& Lane, W. W. Metastatic patterns and target organ arterial blood flow. Invasion Metastasis 1, 126-135 (1981). This study compares the metastatic rate of eight target organs with their arterial blood flow, in the context of colorectal cancer and oesophageal squamous cell carcinoma; the authors observed that the frequency of organ metastasis correlated with blood flow.

13. Headley, M. B. et al. Visualization of immediate immune responses to pioneer metastatic cells in the lung. Nature 531, 513-517 (2016). Using intravital imaging of metastatic dissemination to the lung, this study reveals that shear flow fragments CTCs, thereby generating immune-interacting intermediates that define the efficiency of metastatic cell seeding.

14. Follain, G. et al. Hemodynamic forces tune the arrest, adhesion, and extravasation of circulating tumor cells. Dev. Cell 45, 33-52.e12 (2018).

This paper provides the first demonstration that metastatic dissemination occurs in vascular regions 
with permissive flow profiles, and further shows that metastatic extravasation is facilitated by endothelial remodelling, which is dependent on blood flow forces.

15. Broggi, M. A. S. et al. Tumor-associated factors are enriched in lymphatic exudate compared to plasma in metastatic melanoma patients. J. Exp. Med. 216 1091-1107 (2019)

16. García-Silva, S. et al. Use of extracellular vesicles from lymphatic drainage as surrogate markers of melanoma progression and BRAF ${ }^{V 600 E}$ mutation. J. Exp. Med. 216, 1061-1070 (2019).

17. Bessonov, N., Sequeira, A., Simakov, S., Vassilevskii, Y. \& Volpert, V. Methods of blood flow modelling. Math. Model. Nat. Phenom. 11, 1-25 (2016).

18. Freund, J. B. Numerical simulation of flowing blood cells. Annu. Rev. Fluid Mech. 46, 67-95 (2014).

19. Dixon, J. B. et al. Lymph flow, shear stress, and lymphocyte velocity in rat mesenteric prenodal lymphatics. Microcirculation 13, 597-610 (2006).

20. Peng, S.-L., Shih, C.-T., Huang, C.-W., Chiu, S.-C. \& Shen, W.-C. Optimized analysis of blood flow and wall shear stress in the common carotid artery of rat model by phase-contrast MRI. Sci. Rep. 7, 5253 (2017).

21. Reneman, R. S. \& Hoeks, A. P. G. Wall shear stress as measured in vivo: consequences for the design of the arterial system. Med. Biol. Eng. Comput. 46, 499-507 (2008)

22. Stylianopoulos, T., Munn, L. L. \& Jain, R. K. Reengineering the physical microenvironment of tumors to improve drug delivery and efficacy: from mathematical modeling to bench to bedside. Trends Cancer 4, 292-319 (2018).

23. Levick, J. R. \& Michel, C. C. Microvascular fluid exchange and the revised Starling principle. Cardiovasc. Res. 87, 198-210 (2010).

24. Darcy, H. Les fontaines publiques de la ville de Dijon Exposition et application des principes à suivre et des formules à employer dans les questions de distribution d'eau: ouvrage terminé par un appendice relatif aux fournitures d'eau de plusieurs villes au filtrage des eaux et à la fabrication des tuyaux de fonte, de plomb, de tole et de bitume. (Dalmont, 1856)

25. De Palma, M., Biziato, D. \& Petrova, T. V. Microenvironmental regulation of tumou angiogenesis. Nat. Rev. Cancer 17, 457-474 (2017).

26. Stacker, S. A. et al. Lymphangiogenesis and lymphatic vessel remodelling in cancer. Nat. Rev. Cancer 14 159-172 (2014)

27. Torcellan, T. et al. In vivo photolabeling of tumorinfiltrating cells reveals highly regulated egress of T-cel subsets from tumors. Proc. Natl Acad. Sci. USA 114, 5677-5682 (2017)

28. Baish, J. W., Netti, P. A. \& Jain, R. K. Transmural coupling of fluid flow in microcirculatory network and interstitium in tumors. Microvasc. Res. 53, 128-141 (1997).

29. Jain, R. K. Delivery of molecular medicine to solid tumors: lessons from in vivo imaging of gene expression and function. J. Control. Release 74, 7-25 (2001).

30. Liu, L. J. \& Schlesinger, M. Interstitial hydraulic conductivity and interstitial fluid pressure for avascular or poorly vascularized tumors. J. Theor. Biol. $380,1-8$ (2015)

31. Roose, T., Netti, P. A Munn, L. L., Boucher, Y. $\&$ Jain, R. K. Solid stress generated by spheroid growth estimated using a linear poroelasticity model. Microvasc. Res. 66, 204-212 (2003).

32. Sefidgar, M., Soltani, M., Raahemifar, K. \& Bazmara, H. Effect of fluid friction on interstitial fluid flow coupled with blood flow through solid tumor microvascular network. Comput. Math. Methods Med. 2015, 673426 (2015).

33. Provenzano, P. P. et al. Enzymatic targeting of the stroma ablates physical barriers to treatment of pancreatic ductal adenocarcinoma. Cancer Cell 21. 418-429 (2012)

34. Stylianopoulos, T. et al. Causes, consequences, and remedies for growth-induced solid stress in murine and human tumors. Proc. Natl Acad. Sci. USA 109. 15101-15108 (2012)

35. Milosevic, M. et al. Interstitial permeability and elasticity in human cervix cancer. Microvasc. Res. 75, 381-390 (2008)

36. Baxter, L. T. \& Jain, R. K. Transport of fluid and macromolecules in tumors. I. Role of interstitial pressure and convection. Microvasc. Res. 37, 77-104 (1989).

37. Chary, S. R. \& Jain, R. K. Direct measurement of interstitial convection and diffusion of album normal and neoplastic tissues by fluorescence photobleaching. Proc. Natl Acad. Sci. USA. 86 5385-5389 (1989).

38. Jain, R. K. Transport of molecules, particles, and cells in solid tumors. Annu. Rev. Biomed. Eng. 1, 241-263 (1999).

39. Swartz, M. A. \& Fleury, M. E. Interstitial flow and its effects in soft tissues. Annu. Rev. Biomed. Eng. 9 , 229-256 (2007)

40. Stylianopoulos, T. The solid mechanics of cancer and strategies for improved therapy. J. Biomech. Eng. 139 021004 (2017).

41. Cornelison, R. C., Brennan, C. E., Kingsmore, K. M. \& Munson, J. M. Convective forces increase CXCR4 dependent glioblastoma cell invasion in GL261 murine model. Sci. Rep. 8, 17057 (2018).

42. Huang, Y. L., Tung, C., Zheng, A., Kim, B. J. \& Wu, M Interstitial flows promote amoeboid over mesenchyma motility of breast cancer cells revealed by a three dimensional microfluidic model. Integr. Biol. 7 , 1402-1411 (2015)

43. Harney, A. S. et al. Real-time imaging reveals local, transient vascular permeability, and tumor cell intravasation stimulated by Tie $2^{\text {hi }}$ macrophage-derived VEGFA. Cancer Discov. 5, 932-943 (2015).

44. Li, R. et al. Interstitial flow promotes macrophage polarization toward an M2 phenotype. Mol. Biol. Cell 29, 1927-1940 (2018)

45. Arwert, E. N. et al. A unidirectional transition from migratory to perivascular macrophage is required for tumor cell intravasation. Cell Rep. 23, 1239-1248 (2018).

46. Pisano, M., Triacca, V., Barbee, K. A. \& Swartz, M. A. An in vitro model of the tumor-lymphatic microenvironment with simultaneous transendothelial and luminal flows reveals mechanisms of flow enhanced invasion. Integr. Biol. 7, 525-533 (2015).

47. Sänger, N. et al. Disseminated tumor cells in the bone marrow of patients with ductal carcinoma in situ. Int. J. Cancer 129, 2522-2526 (2011).

48. $\mathrm{Hu}, \mathrm{Z}$. et al. Quantitative evidence for early metastatic seeding in colorectal cancer. Nat. Genet. $\mathbf{5 1}$ 1113-1122 (2019).

49. Rhim, A. D. et al. EMT and dissemination precede pancreatic tumor formation. Cell 148, 349-361 (2012)

50. Hüsemann, Y. et al. Systemic spread is an early step in breast cancer. Cancer Cell 13, 58-68 (2008).

51. Hosseini, H. et al. Early dissemination seeds metastasis in breast cancer. Nature 540, 552-558 (2016).

52. Harper, K. L. et al. Mechanism of early dissemination and metastasis in Her2+ mammary cancer. Nature 540, 588-592 (2016).

53. Aceto, N. et al. Circulating tumor cell clusters are oligoclonal precursors of breast cancer metastasis. Cell 158, 1110-1122 (2014)

This paper shows that CTCs can be found as clusters in the bloodstream that display increased metastatic potential, and further shows that plakoglobin mediates intravascular cluster formation through intercellular adhesion.

54. Nathanson, S. D. Insights into the mechanisms of lymph node metastasis. Cancer 98, 413-423 (2003).

55. Wong, S. Y. \& Hynes, R. O. Lymphatic or hematogenous dissemination: how does a metastatic tumor cell decide? Cell Cycle 5, 812-817 (2006)

56. Jones, D., Pereira, E. R. \& Padera, T. P. Growth and immune evasion of lymph node metastasis. Front. Oncol. 8, 36 (2018).

57. Faries, M. B. et al. Completion dissection or observation for sentinel-node metastasis in melanoma. N. Engl. J. Med. 376, 2211-2222 (2017)

58. Costa-Silva, B. et al. Pancreatic cancer exosomes initiate pre-metastatic niche formation in the liver. Nat. Cell Biol. 17, 816-826 (2015).

59. Cox, T. R. et al. The hypoxic cancer secretome induces pre-metastatic bone lesions through lysyl oxidase. Nature 522, 106-110 (2015).

60. Hoshino, A. et al. Tumour exosome integrins determine organotropic metastasis. Nature $\mathbf{5 2 7}$ 329-335 (2015)

61. Kaplan, R. N. et al. VEGFR1-positive haematopoietic bone marrow progenitors initiate the pre-metastatic niche. Nature 438, 820-827 (2005).

62. Peinado, $\mathrm{H}$. et al. Melanoma exosomes educate bone marrow progenitor cells toward a pro-metastatic phenotype through MET. Nat. Med. 18, 883-89 (2012).

63. Zomer, A. et al. In vivo imaging reveals extracellular vesicle-mediated phenocopying of metastatic behavior. Cell 161, 1046-1057 (2015).

This study uses intravital imaging to track the local and distant dissemination of EVs, demonstrating that their uptake can shape metastatic fitness.

64. Weber, M. et al. Interstitial dendritic cell guidance by haptotactic chemokine gradients. Science 339 , 328-332 (2013)

65. Moravec, R., Divi, R. \& Verma, M. Detecting circulating tumor material and digital pathology imaging during pancreatic cancer progression. World J. Gastrointest. Oncol. 9, 235-250 (2017).

66. Pantel, K. \& Alix-Panabières, C. Liquid biopsy and minimal residual disease-latest advances and implications for cure. Nat. Rev. Clin. Oncol. 16 409-424 (2019).

67. Morishita, M. et al. Quantitative analysis of tissue distribution of the B16BL6-derived exosomes using a streptavidin-lactadherin fusion protein and iodine125-labeled biotin derivative after intravenous injection in mice. J. Pharm. Sci. 104, 705-713 (2015).

68. Saunderson, S. C., Dunn, A. C., Crocker, P. R. \& McLellan, A. D. CD169 mediates the capture of exosomes in spleen and lymph node. Blood 123 208-216 (2014)

69. Diehl, F. et al. Circulating mutant DNA to assess tumor dynamics. Nat. Med. 14, 985-990 (2008).

70. Imai, T. et al. Macrophage-dependent clearance of systemically administered B16BL6-derived exosomes from the blood circulation in mice. J. Extracell. Vesicles 4, 26238 (2015).

71. Hyenne, V. et al. Studying the fate of tumor extracellular vesicles at high spatiotemporal resolution using the zebrafish embryo. Dev. Cell 48, 554-572. e7 (2019)

72. Chennakrishnaiah, S. et al. Leukocytes as a reservoir of circulating oncogenic DNA and regulatory targets of tumor-derived extracellular vesicles. J. Thromb. Haemost. 16, 1800-1813 (2018).

73. Toy, R., Hayden, E., Shoup, C., Baskaran, H. \& Karathanasis, E. The effects of particle size, density and shape on margination of nanoparticles in microcirculation. Nanotechnology 22, 115101 (2011).

74. Müller, K., Fedosov, D. A. \& Gompper, G. Margination of micro- and nano-particles in blood flow and its effect on drug delivery. Sci. Rep. 4, 4871 (2014).

75. Zhang, $\mathrm{H}$. et al. Identification of distinct nanoparticles and subsets of extracellular vesicles by asymmetric flow field-flow fractionation. Nat. Cell Biol. 20 332-343 (2018)

76. Di Vizio, D. et al. Oncosome formation in prostate cancer: association with a region of frequent chromosomal deletion in metastatic disease. Cancer Res. 69, 5601-5609 (2009).

77. De Jong, W. H. et al. Particle size-dependent organ distribution of gold nanoparticles after intravenous administration. Biomaterials 29, 1912-1919 (2008).

78. Regmi, S., Fu, A. \& Luo, K. Q. High shear stresses under exercise condition destroy circulating tumor cells in a microfluidic system. Sci. Rep. 7, 39975 (2017).

79. Srinivasan, S., Vannberg, F. O. \& Dixon, J. B. Lymphatic transport of exosomes as a rapid route of information dissemination to the lymph node. Sci. Rep. 6, 24436 (2016).

80. Hood, J. L., San, R. S. \& Wickline, S. A. Exosomes released by melanoma cells prepare sentinel lymph nodes for tumor metastasis. Cancer Res. 71 3792-3801 (2011).

81. Pucci, F. et al. SCS macrophages suppress melanoma by restricting tumor-derived vesicle-B cell interactions. Science 352, 242-246 (2016).

82. Moalli, F. et al. Intravital and whole-organ imaging reveals capture of melanoma-derived antigen by lymph node subcapsular macrophages leading to widespread deposition on follicular dendritic cells. Front. Immunol 6, 114 (2015).

83. Miyamura, Y. et al. Drainage of tumor-derived DNA into sentinel lymph nodes in breast cancer patients. Pathol. Oncol. Res. 25, 1635-1643 (2019).

84. Olmeda, D. et al. Whole-body imaging of lymphovascular niches identifies pre-metastatic roles of midkine. Nature 546, 676-680 (2017).

85. Liu, Y. \& Cao, X. Characteristics and significance of the pre-metastatic niche. Cancer Cell 30, 668-681 (2016).

86. Zhou, W. et al. Cancer-secreted miR-105 destroys vascular endothelial barriers to promote metastasis. Cancer Cell 25, 501-515 (2014).

87. Treps, L. et al. Extracellular vesicle-transported Semaphorin3A promotes vascular permeability in glioblastoma. Oncogene 35, 2615-2623 (2016). 
88. Tominaga, N. et al. Brain metastatic cancer cells release microRNA-181 c-containing extracellular vesicles capable of destructing blood-brain barrier. Nat. Commun. 6, 6716 (2015)

89. Verweij, F. J. et al. Live tracking of inter-organ communication by endogenous exosomes in vivo. Dev. Cell 48, 573-589.e4 (2019).

90. Chambers, A. F., Groom, A. C. \& MacDonald, I. C Metastasis: dissemination and growth of cancer cells in metastatic sites. Nat. Rev. Cancer 2, 563-572 (2002).

91. Anton, H. et al. Pulse propagation by a capacitive mechanism drives embryonic blood flow. Development 140, 4426-4434 (2013).

92. Ku, D. N. Blood flow in arteries. Annu. Rev. Fluid Mech. 29, 399-434 (1997).

93. Tanaka, T. et al. Inertial migration of cancer cells in blood flow in microchannels. Biomed. Microdevices 14, 25-33 (2012).

94. Jolly, M. K. et al. Inflammatory breast cancer: a model for investigating cluster-based dissemination. NPJ Breast Cancer 3, 21 (2017).

95. Rejniak, K. A. Circulating tumor cells: when a solid tumor meets a fluid microenvironment. Adv. Exp. Med. Biol. 936, 93-106 (2016).

96. Anderson, K. J., de Guillebon, A., Hughes, A. D., Wang, W. \& King, M. R. Effect of circulating tumor cell aggregate configuration on hemodynamic transport and wall contact. Math. Biosci. 294, 181-194 (2017)

97. Hong, Y., Fang, F. \& Zhang, Q. Circulating tumor cell clusters: what we know and what we expect [Review] Int. J. Oncol. 49, 2206-2216 (2016).

98. Gassmann, P., Hemping-Bovenkerk, A., Mees, S. T. \& Haier, J. Metastatic tumor cell arrest in the liverlumen occlusion and specific adhesion are not exclusive. Int. J. Colorectal Dis. 24, 851-858 (2009).

99. Kienast, Y. et al. Real-time imaging reveals the single steps of brain metastasis formation. Nat. Med. 16, 116-122 (2010)

This paper uses longitudinal real-time intravital imaging to provide a clear description of intravascular steps during brain metastasis formation; the authors show that arrest of CTCs at vascular branch points of microvessels is a key step in metastatic progression, offering a very useful in vivo approach for tracking intravascular behaviour of CTCs.

100. Mitchell, M. J. \& King, M. R. Computational and experimental models of cancer cell response to fluid shear stress. Front. Oncol. 3, 44 (2013).

101. Prothero, J. \& Burton, A. C. The physics of blood flow in capillaries. Biophys. J. 7, 565-579 (1961).

102. Tawhai, M. H. \& Burrowes, K. S. Modelling pulmonary blood flow. Respir. Physiol. Neurobiol. 163, 150-157 (2008).

103. Mauroy, B. Following red blood cells in a pulmonary capillary. ESAIM. Proceedings 23, 48-65 (2008).

104. Rejniak, K. A Investigating dynamical deformations of tumor cells in circulation: predictions from a theoretical model. Front. Oncol. 2, 111 (2012).

105. King, M. R. et al. A physical sciences network characterization of circulating tumor cell aggregate transport. Am. J. Physiol. Cell Physiol. 308 C792-C802 (2015)

106. Takeishi, N., Imai, Y., Yamaguchi, T. \& Ishikawa, T. Flow of a circulating tumor cell and red blood cells in microvessels. Phys. Rev. E. Stat. Nonlin. Soft Matter Phys. 92, 063011 (2015).

107. Phillips, K. G. et al. The thrombotic potential of circulating tumor microemboli: computational modeling of circulating tumor cell-induced coagulation. Am. J. Physiol. Cell Physiol. 308 C229-C236 (2015)

108. Luzzi, K. J. et al. Multistep nature of metastatic inefficiency. Am. J. Pathol. 153, 865-873 (1998).

109. Cameron, M. D. et al. Temporal progression of metastasis in lung: cell survival, dormancy, and location dependence of metastatic inefficiency. Cancer Res. 60, 2541-2546 (2000)

110. van der Weyden, L. et al. Genome-wide in vivo screen identifies novel host regulators of metastatic colonization. Nature 541, 233-236 (2017).

111. Basnet, H. et al. Flura-seq identifies organ-specific metabolic adaptations during early metastatic colonization. eLife 8, e43627 (2019).

112. Chang, S.-F. et al. Tumor cell cycle arrest induced by shear stress: roles of integrins and Smad. Proc. Nat Acad. Sci. USA 105, 3927-3932 (2008).

113. Regmi, S., Fung, T. S., Lim, S. \& Luo, K. O. Fluidic shear stress increases the anti-cancer effects of ROS-generating drugs in circulating tumor cells. Breast Cancer Res. Treat. 172, 297-312 (2018).
114. Mitchell, M. J. et al. Lamin A/C deficiency reduces circulating tumor cell resistance to fluid shear stress. Am. J. Physiol. Cell Physiol. 309, C736-C746 (2015) This study shows that tumour cells are resistant to shear forces and display reduced apoptosis and necrosis relative to normal cells; the paper further shows that such resistance is mediated by lamin $\mathrm{A} / \mathrm{C}$, which acts as a structural component and facilitates survival.

115. Lien, S.-C. et al. Mechanical regulation of cancer cell apoptosis and autophagy: roles of bone morphogenetic protein receptor, Smad1/5, and p38 MAPK. Biochim. Biophys. Acta 1833, 3124-3133 (2013).

116. Mitchell, M. J. \& King, M. R. Fluid shear stress sensitizes cancer cells to receptor-mediated apoptosis via trimeric death receptors. New J. Phys. 15, 015008 (2013).

117. Barnes, J. M., Nauseef, J. T. \& Henry, M. D. Resistance to fluid shear stress is a conserved biophysical property of malignant cells. PLOS ONE 7, e50973 (2012).

118. Terasaki, M., Miyake, K. \& McNeil, P. L. Large plasma membrane disruptions are rapidly resealed by $\mathrm{Ca}^{2+}$ dependent vesicle-vesicle fusion events. J. Cell Biol. 139, 63-74 (1997).

119. Lammerding, J. et al. Lamins $A$ and $C$ but not Lamin B1 regulate nuclear mechanics. J. Biol. Chem. 281 25768-25780 (2006)

120. Woroniuk, A. et al. STEF/TIAM2-mediated Rac activity at the nuclear envelope regulates the perinuclear actin cap. Nat. Commun. 9, 2124 (2018).

121. Gong, C. et al. Potentiated DNA damage response in circulating breast tumor cells confers resistance to chemotherapy. J Biol. Chem. 290, 14811-14825 (2015).

122. Zheng, Y. et al. Expression of $\beta$-globin by cancer cells promotes cell survival during blood-borne dissemination. Nat. Commun. 8, 14344 (2017).

123. Fu, A. et al. High expression of MnSOD promotes survival of circulating breast cancer cells and increases their resistance to doxorubicin. Oncotarget 7 . 50239-50257 (2016).

124. Piskounova, E. et al. Oxidative stress inhibits distant metastasis by human melanoma cells. Nature $\mathbf{5 2 7}$, 186-191 (2015)

125. Strilic, B. \& Offermanns, S. Intravascular survival and extravasation of tumor cells. Cancer Cell 32 282-293 (2017)

126. Hamidi, H. \& Ivaska, J. Every step of the way: integrin in cancer progression and metastasis. Nat. Rev. Cance 18, 533-548 (2018)

127. Desgrosellier, J. S. et al. An integrin $\alpha_{v} \beta_{3}-c-S r c$ oncogenic unit promotes anchorage-independence and tumor progression. Nat. Med. 15, 1163-1169 (2009).

128. Alanko, J. et al. Integrin endosomal signalling suppresses anoikis. Nat. Cell Biol. 17, 1412-1421 (2015).

129. Aslan, B. et al. The ZNF304-integrin axis protects against anoikis in cancer. Nat. Commun. 6, 7351 (2015).

130. Douma, S. et al. Suppression of anoikis and induction of metastasis by the neurotrophic receptor TrkB. Nature 430, 1034-1039 (2004).

131. Sun, B. et al. Midkine promotes hepatocellular carcinoma metastasis by elevating anoikis resistance of circulating tumor cells. Oncotarget 8 32523-32535 (2017).

132. Lee, H. J. et al. Fluid shear stress activates YAP1 to promote cancer cell motility. Nat. Commun. 8, 14122 (2017).

133. Lee, H. J., Ewere, A., Diaz, M. F. \& Wenzel, P. L. TAZ responds to fluid shear stress to regulate the cell cycle. Cell Cycle 17, 147-153 (2018).

134. Derynck, R. \& Weinberg, R. A. EMT and cancer: more than meets the eye. Dev. Cell 49, 313-316 (2019).

135. Lamouille, S., Xu, J. \& Derynck, R. Molecular mechanisms of epithelial-mesenchymal transition. Nat. Rev. Mol. Cell Biol. 15, 178-196 (2014).

136. Rizvi, I. et al. Flow induces epithelial-mesenchymal transition, cellular heterogeneity and biomarker modulation in 3D ovarian cancer nodules. Proc. Nat Acad. Sci. USA. 110, E1974-E1983 (2013). This study uses microfluidic approaches to show that flow forces increase EMT of tumour cells and favour their motility and aggressiveness.

137. Yu, M. et al. Circulating breast tumor cells exhibit dynamic changes in epithelial and mesenchyma composition. Science 339, 580-584 (2013)

138. Baccelli, I. et al. Identification of a population of blood circulating tumor cells from breast cancer patients that initiates metastasis in a xenograft assay Nat. Biotechnol 31, 539-544 (2013).

139. Beerling, E. et al. Plasticity between epithelial and mesenchymal states unlinks EMT from metastasisenhancing stem cell capacity. Cell Rep. 14 2281-2288 (2016).

140. Erami, Z. et al. Intravital FRAP imaging using an E-cadherin-GFP mouse reveals disease- and drug-dependent dynamic regulation of cell-cell junctions in live tissue. Cell Rep. 14, 152-167 (2016)

141. Ting, D. T. et al. Single-cell RNA sequencing identifies extracellular matrix gene expression by pancreatic circulating tumor cells. Cell Rep. 8, 1905-1918 (2014).

142. Choi, H. Y. et al. Hydrodynamic shear stress promotes epithelial-mesenchymal transition by downregulating ERK and CSK3 $\beta$ activities. Breast Cancer Res. 21, 6 (2019).

143. Xin, Y. et al. Mechanics and actomyosin-dependent survival/chemoresistance of suspended tumor cells in shear flow. Biophys. J. 116, 1803-1814 (2019).

144. Moazzam, F., DeLano, F. A., Zweifach, B. W. \& Schmid-Schönbein, G. W. The leukocyte response to fluid stress. Proc. Natl Acad. Sci. USA 94 5338-5343 (1997).

145. Guido, S. \& Tomaiuolo, G. Microconfined flow behavior of red blood cells in vitro. Comptes Rendus Phys. 10 751-763 (2009)

146. Xiao, L. L., Liu, Y., Chen, S. \& Fu, B. M. Effects of flowing RBCs on adhesion of a circulating tumor cell in microvessels. Biomech. Model. Mechanobiol. 16 597-610 (2017)

147. Padmanaban, V. et al. E-cadherin is required for metastasis in multiple models of breast cancer. Nature 573, 439-444 (2019).

148. Zhuang, X. \& Long, E. O. CD28 homolog is a strong activator of natural killer cells for lysis of $\mathrm{B} 7 \mathrm{H} 7^{+}$tumo cells. Cancer Immunol. Res. 7, 939-951 (2019).

149. Cheung, K. J. et al. Polyclonal breast cancer metastases arise from collective dissemination of keratin 14-expressing tumor cell clusters. Proc. Natl Acad. Sci. USA 113, E854-E863 (2016).

150. Liu, X. et al. Homophilic CD44 interactions mediate tumor cell aggregation and polyclonal metastasis in patient-derived breast cancer models. Cancer Discov. 9, 96-113 (2019).

151. Chaffer, C. L. et al. Poised chromatin at the ZEB promoter enables breast cancer cell plasticity and enhances tumorigenicity. Cell 154, 61-74 (2013).

152. Al-Haji, M., Wicha, M. S., Benito-Hernandez, A., Morrison, S. J. \& Clarke, M. F. Prospective identification of tumorigenic breast cancer cells. Proc. Natl Acad. Sci. USA 100, 3983-3988 (2003).

153. Au, S. H et al. Clusters of circulating tumor cells traverse capillary-sized vessels. Proc. Natl Acad. Sci. USA 113, 4947-4952 (2016) This paper shows that clusters of CTCs can successfully flow through vessel constrictions; they reduce their hydrodynamic resistance by reorganizing into single-file chain-like clusters.

154. Ao, Z. et al. Identification of cancer associated fibroblasts in circulating blood from patients with metastatic breast cancer. Cancer Res. 75 4681-4687 (2015).

155. Duda, D. G. et al. Malignant cells facilitate lung metastasis by bringing their own soil. Proc. Natl Acad Sci. USA 107, 21677-21682 (2010)

156. McCarroll, J. A. et al. Role of pancreatic stellate cells in chemoresistance in pancreatic cancer. Front. Physiol. 5, 141 (2014).

157. Kärre, K. Express yourself or die: peptides, MHC molecules, and NK cells. Science 267, 978-979 (1995).

158. Spicer, J. D. et al. Neutrophils promote liver metastasis via Mac-1-mediated interactions with circulating tumor cells. Cancer Res. 72, 3919-3927 (2012).

159. Szczerba, B. M. et al. Neutrophils escort circulating tumour cells to enable cell cycle progression. Nature 566, 553-557 (2019).

This paper shows that clusters of CTCs are accompanied by neutrophils; the presence of neutrophils was associated with cell cycle progression in CTCs within the bloodstream, thereby promoting their metastatic potential.

160. Strell, C., Lang, K., Niggemann, B., Zaenker, K. S. $\&$ Entschladen, F. Surface molecules regulating rolling and adhesion to endothelium of neutrophil granulocytes and MDA-MB-468 breast carcinoma 
cells and their interaction. Cell. Mol. Life Sci. 64 , 3306-3316 (2007).

161. Chen, M. B. et al. Inflamed neutrophils sequestered at entrapped tumor cells via chemotactic confinement promote tumor cell extravasation. Proc. Natl Acad. Sci. USA. 115, 7022-7027 (2018).

162. Bambace, N. M. \& Holmes, C. E. The platelet contribution to cancer progression. J. Thromb. Haemost. 9, 237-249 (2011).

163. Gasic, G. J., Gasic, T. B. \& Stewart, C. C. Antimetastatic effects associated with platelet reduction. Proc. Natl Acad. Sci. USA 61, 46-52 (1968).

164. Ilkan, Z. et al. Evidence for shear-mediated $\mathrm{Ca}^{2+}$ entry through mechanosensitive cation channels in human platelets and a megakaryocytic cell line. J. Biol. Chem. 292, 9204-9217 (2017).

165. Labelle, M., Begum, S. \& Hynes, R. O. Direct signaling between platelets and cancer cells induces an epithelial-mesenchymal-like transition and promotes metastasis. Cancer Cell 20, 576-590 (2011).

166. Labelle, M., Begum, S. \& Hynes, R. O. Platelets guide the formation of early metastatic niches. Proc. Natl Acad. Sci. USA 111, E3053-E3061 (2014).

167. Frenette, P. S., Johnson, R. C., Hynes, R. O. $\&$ Wagner, D. D. Platelets roll on stimulated endothelium in vivo: an interaction mediated by endothelial P-selectin. Proc. Natl Acad. Sci. USA 92 7450-7454 (1995).

168. Reymond, N., d'Ägua, B. B. \& Ridley, A. J. Crossing the endothelial barrier during metastasis. Nat. Rev. Cancer 13, 858-870 (2013).

169. Haemmerle, M. et al. Platelets reduce anoikis and promote metastasis by activating YAP1 signaling. Nat. Commun. 8, 310 (2017)

170. Echtler, K. et al. Platelet GPIlb supports initial pulmonary retention but inhibits subsequent proliferation of melanoma cells during hematogenic metastasis. PLOS ONE 12, e0172788 (2017).

171. Erpenbeck, L., Nieswandt, B., Schön, M., Pozgajova, M $\&$ Schön, M. P. Inhibition of platelet GPIb $\alpha$ and promotion of melanoma metastasis. J. Invest. Dermatol. 130, 576-586 (2010)

172. Valastyan, S. \& Weinberg, R. A. Tumor metastasis: molecular insights and evolving paradigms. Cell 147, 275-292 (2011)

173. Al-Mehdi, A. B. et al. Intravascular origin of metastasis from the proliferation of endothelium-attached tumor cells: a new model for metastasis. Nat. Med. $\mathbf{6}$, 100-102 (2000)

174. Chen, M. B., Whisler, J. A., Jeon, J. S. \& Kamm, R. D. Mechanisms of tumor cell extravasation in an in vitro microvascular network platform. Integr. Biol. 5, 1262-1271 (2013)

175. Stoletov, K., Montel, V., Lester, R. D., Gonias, S. L. \& Klemke, R. High-resolution imaging of the dynamic tumor cell-vascular interface in transparent zebrafish. Proc. Natl Acad. Sci. USA 104, 17406-17411 (2007).

176. Bell, G. I. A theoretical model for adhesion between cells mediated by multivalent ligands. Cell Biochem. Biophys. 1, 133-147 (1979)

177. Bell, G. I., Dembo, M. \& Bongrand, P. Cell adhesion Competition between nonspecific repulsion and specific bonding. Biophys. J. 45, 1051-1064 (1984).

178. Marshall, B. T. et al. Direct observation of catch bonds involving cell-adhesion molecules. Nature $\mathbf{4 2 3}$ 190-193 (2003)

179. Alon, R. \& Feigelson, S. W. Chemokine-triggered leukocyte arrest: force-regulated bi-directional integrin activation in quantal adhesive contacts. Curr. Opin. Cell Biol. 24, 670-676 (2012).

180. Aigner, S. et al. CD24 mediates rolling of breast carcinoma cells on P-selectin. FASEB J.12, 1241-1251 (1998)

181. Schaefer, A. \& Hordijk, P. L. Cell-stiffness-induced mechanosignaling-a key driver of leukocyte transendothelial migration. J. Cell Sci. 128 2221-2230 (2015)

182. Vestweber, D. How leukocytes cross the vascular endothelium. Nat. Rev. Immunol. 15, 692-704 (2015)

83. Kong, F. et al. Cyclic mechanical reinforcement of integrin-ligand interactions. Mol. Cell 49, 1060-1068 (2013)

184. Osmani, N. et al. Metastatic tumor cells exploit their adhesion repertoire to counteract shear forces during intravascular arrest. Cell Rep. 28, 2491-2500.e5 (2019)

185. Liu, T.-L. et al. Observing the cell in its native state: imaging subcellular dynamics in multicellular organisms. Science 360, eaaq1392 (2018).

186. Stoletov, K. et al. Visualizing extravasation dynamics of metastatic tumor cells. J. Cell Sci. 123, 2332-2341 (2010)
187. Hiratsuka, S. et al. Endothelial focal adhesion kinase mediates cancer cell homing to discrete regions of the lungs via E-selectin up-regulation. Proc. Natl Acad. Sci. USA 108, 3725-3730 (2011).

188. Fan, R. et al. Circulatory shear flow alters the viability and proliferation of circulating colon cancer cells. Sci. Rep. 6, 27073 (2016).

189. Entenberg, D. et al. A permanent window for the murine lung enables high-resolution imaging of cancer metastasis. Nat. Methods 15, 73-80 (2018).

This study provides methodologies for stably tracking the formation of lung metastases in a mouse model, enabling the accurate tracking of the intravascular arrival of CTCs, extravasation, growth and progression to micrometastases.

190. Lautscham, L. A. et al. Migration in confined $3 \mathrm{D}$ environments is determined by a combination of adhesiveness, nuclear volume, contractility, and cell stiffness. Biophys. J. 109, 900-913 (2015).

191. Raab, M. et al. ESCRT III repairs nuclear envelope ruptures during cell migration to limit DNA damage and cell death. Science 352, 359-362 (2016).

192. Denais, C. M. et al. Nuclear envelope rupture and repair during cancer cell migration. Science 352 353-358 (2016)

193. Infante, E. et al. LINC complex-Lis1 interplay controls MT1-MMP matrix digest-on-demand response for confined tumor cell migration. Nat. Commun. 9, 2443 (2018).

194. Leong, H. S. et al. Invadopodia are required for cancer cell extravasation and are a therapeutic target for metastasis. Cell Rep 8, 1558-1570 (2014).

195. Williams, K. C. et al. Invadopodia are chemosensing protrusions that guide cancer cell extravasation to promote brain tropism in metastasis. Oncogene 38 3598-3615 (2019).

196. Warren, S. C. et al. Removing physiological motion from intravital and clinical functional imaging data. elife 7, e35800 (2018)

This study highlights the application of intravital Förster resonance energy transfer imaging to characterize signalling dynamics that might be involved in cancer cell extravasation and arrival at secondary sites; the publication also characterizes a novel software tool that can be used to correct for sample motion, a major challenge commonly encountered in intravital imaging due to animal respiration or heartbeat.

197. Lapis, K., Paku, S. \& Liotta, L. A. Endothelialization of embolized tumor cells during metastasis formation. Clin. Exp. Metastasis 6, 73-89 (1988).

198. Lam, C. K., Yoo, T., Hiner, B., Liu, Z. \& Grutzendler, J. Embolus extravasation is an alternative mechanism for cerebral microvascular recanalization. Nature $\mathbf{4 6 5}$ 478-482 (2010).

199. Ghajar, C. M. et al. The perivascular niche regulates breast tumor dormancy. Nat. Cell Biol. 15, 807-817 (2013).

200. Carlson, P. et al. Targeting the perivascular niche sensitizes disseminated tumour cells to chemotherapy. Nat. Cell Biol. 21, 238-250 (2019).

201. Heyder, C. et al. Realtime visualization of tumo cell/endothelial cell interactions during transmigration across the endothelial barrier. J. Cancer Res. Clin Oncol. 128, 533-538 (2002).

202. Strilic, B et al. Tumour-cell-induced endothelial cell necroptosis via death receptor 6 promotes metastasis. Nature 536, 215-218 (2016)

203. Miyamoto, D. T., Ting, D. T., Toner, M., Maheswaran, S. $\&$ Haber, D. A. Single-cell analysis of circulating tumor cells as a window into tumor heterogeneity. Cold Spring Harb. Symp. Quant. Biol. 81, 269-274 (2016).

204. Hu, L., Lee, M., Campbell, W., Perez-Soler, R. \& Karpatkin, S. Role of endogenous thrombin in tumor implantation, seeding, and spontaneous metastasis. Blood 104, 2746-2751 (2004)

205. Goertz, L et al. Heparins that block VEGF-A-mediated von Willebrand factor fiber generation are potent inhibitors of hematogenous but not lymphatic metastasis. Oncotarget 7, 68527-68545 (2016)

206. Bauer, A. T. et al. von Willebrand factor fibers promote cancer-associated platelet aggregation in malignant melanoma of mice and humans. Blood 125 , 3153-3163 (2015)

207. Sloan, E. K. et al. The sympathetic nervous system induces a metastatic switch in primary breast cancer. Cancer Res. 70, 7042-7052 (2010).

208. Le, C. P. et al. Chronic stress in mice remodels lymph vasculature to promote tumour cell dissemination. Nat. Commun. 7, 10634 (2016).
209. Kim, T.-H. et al. Cancer cells become less deformable and more invasive with activation of $\beta$-adrenergic signaling. J. Cell Sci. 129, 4563-4575 (2016).

210. Shaashua, L. et al. Perioperative COX-2 and $\beta$-adrenergic blockade improves metastatic biomarkers in breast cancer patients in a phase-ll randomized trial. Clin. Cancer Res. 23, 4651-4661 (2017).

211. Tanaka, N. et al. Prognonstic impact of reninangiotensin system blockade in localised upper-tract urothelial carcinoma. Br. J. Cancer 106, 290-296 (2012).

212. Lever, A. F. et al. Do inhibitors of angiotensinI-converting enzyme protect against risk of cancer? Lancet 352, 179-184 (1998)

213. Pinter, M. \& Jain, R. K. Targeting the reninangiotensin system to improve cancer treatment: implications for immunotherapy. Sci. Transl. Med. 9 eaan5616 (2017).

214. Diop-Frimpong, B., Chauhan, V. P., Krane, S., Boucher, Y. $\&$ Jain, R. K. Losartan inhibits collagen I synthesis and improves the distribution and efficacy of nanotherapeutics in tumors. Proc. Natl Acad. Sci. USA 108, 2909-2914 (2011)

215. Chauhan, V. P. et al. Angiotensin inhibition enhances drug delivery and potentiates chemotherapy by decompressing tumour blood vessels. Nat. Commun. 4, 2516 (2013).

216. Vennin, C. et al. Transient tissue priming via ROCK inhibition uncouples pancreatic cancer progression, sensitivity to chemotherapy, and metastasis. Sci. Transl. Med. 9, eaai8504 (2017).

217. Bhowmick, T., Berk, E., Cui, X., Muzykantov, V. R. \& Muro, S. Effect of flow on endothelial endocytosis of nanocarriers targeted to ICAM-1. J. Control. Release 157, 485-492 (2012)

218. Raghavan, V., Rbaibi, Y., Pastor-Soler, N. M., Carattino, M. D. \& Weisz, O. A. Shear stressdependent regulation of apical endocytosis in renal proximal tubule cells mediated by primary cilia Proc. Natl Acad. Sci. USA 111, 8506-8511 (2014).

219. Jain, R. K., Martin, J. D. \& Stylianopoulos, T. The role of mechanical forces in tumor growth and therapy. Annu. Rev. Biomed. Eng. 16, 321-346 (2014).

220. Pathak, A. P., Artemov, D., Neeman, M. \& Bhujwalla, Z. M. Lymph node metastasis in breast cancer xenografts is associated with increased regions of extravascular drain, lymphatic vessel area, and invasive phenotype. Cancer Res. 66, 5151-5158 (2006).

221. Polacheck, W. J., Charest, J. L. \& Kamm, R. D. Interstitial flow influences direction of tumor cell migration through competing mechanisms. Proc. Natl Acad. Sci. USA 108, 11115-11120 (2011).

222. Polacheck, W. J., German, A. E., Mammoto, A. Ingber, D. E. \& Kamm, R. D. Mechanotransduction of fluid stresses governs 3D cell migration. Proc. Natl Acad. Sci. USA 111, 2447-2452 (2014).

223. Angeli, S. \& Stylianopoulos, T. Biphasic modeling of brain tumor biomechanics and response to radiation treatment. J. Biomech. 49, 1524-1531 (2016).

224. Shi, Z.-D. \& Tarbell, J. M. Fluid flow mechanotransduction in vascular smooth muscle cells and fibroblasts. Ann. Biomed. Eng. 39, 1608-1619 (2011).

225. Shields, J. D. et al. Autologous chemotaxis as a mechanism of tumor cell homing to lymphatics via interstitial flow and autocrine CCR7 signaling. Cancer Cell 11, 526-538 (2007)

226. Qazi, H., Shi, Z.-D. \& Tarbell, J. M. Fluid shear stress regulates the invasive potential of glioma cells via modulation of migratory activity and matrix metalloproteinase expression. PLOS ONE 6, e20348 (2011).

227. Butcher, D. T., Alliston, T. \& Weaver, V. M. A tens situation: forcing tumour progression. Nat. Rev. Cancer 9, 108-122 (2009).

228. Blatter, C. et al. In vivo label-free measurement of lymph flow velocity and volumetric flow rates using Doppler optical coherence tomography. Sci. Rep. 6 29035 (2016)

229. Hagendoorn, J. et al. Endothelial nitric oxide synthase regulates microlymphatic flow via collecting lymphatics. Circ. Res. 95, 204-209 (2004).

230. Rane, S. et al. Clinical feasibility of noninvasive visualization of lymphatic flow with principles of spin labeling MR imaging: implications for lymphedema assessment. Radiology 269, 893-902 (2013).

231. Northcott, J. M., Dean, I. S., Mouw, J. K. \& Weaver, V. M. Feeling stress: the mechanics of cancer progression and aggression. Front. Cell Dev. Biol. 6, 17 (2018).

232. Dixon, J. B., Gashev, A. A., Zawieja, D. C., Moore, J. E. \& Cote, G. L. Image correlation algorithm for 
measuring lymphocyte velocity and diameter changes in contracting microlymphatics. Ann. Biomed. Eng. 35 387-396 (2007)

233. Aird, W. C. Spatial and temporal dynamics of the endothelium. J. Thromb. Haemost. 3, 1392-1406 (2005).

234. Gray, K. M. \& Stroka, K. M. Vascular endothelial cell mechanosensing: new insights gained from biomimetic microfluidic models. Semin. Cell Dev. Biol. 71 106-117 (2017).

235. Kamiya, A., Bukhari, R. \& Togawa, T. Adaptive regulation of wall shear stress optimizing vascular tree function. Bull. Math. Biol. 46, 127-137 (1984).

236. Aaslid, R., Markwalder, T.-M. \& Nornes, H. Noninvasive transcranial Doppler ultrasound recording of flow velocity in basal cerebral arteries. J. Neurosurg. 57, 769-774 (1982).

237. Bishop, C. C., Powell, S., Rutt, D. \& Browse, N. L. Transcranial Doppler measurement of middle cerebral artery blood flow velocity: a validation study. Stroke 17, 913-915 (1986).

238. Fronek, A., Coel, M. \& Berstein, E. F. Quantitative ultrasonographic studies of lower extremity flow velocities in health and disease. Circulation $\mathbf{5 3}$, 957-960 (1976)

239. Hennerici, M., Rautenberg, W., Sitzer, G. \& Schwartz, A. Transcranial Doppler ultrasound for the assessment of intracranial arterial flow velocityPart 1. Examination technique and normal values. Surg. Neurol. 27, 439-448 (1987)

240. Reinitz, A., DeStefano, J., Ye, M., Wong, A. D. \& Searson, P. C. Human brain microvascular endothelial cells resist elongation due to shear stress. Microvasc. Res. 99, 8-18 (2015)

241. Segadal, L. \& Matre, K. Blood velocity distribution in the human ascending aorta. Circulation 76, 90-100 (1987).

242. Brookes, M. Arteriolar blockade: a method of measuring blood flow rates in the skeleton. J. Anat. 106, 557-563 (1970).

243. Ashikawa, K., Kanatsuka, H., Suzuki, T. \& Takishima, T. Phasic blood flow velocity pattern in epimyocardial microvessels in the beating canine left ventricle. Circ. Res. 59, 704-711 (1986)

244. Coffman, J. D. \& Lempert, J. A. Venous flow velocity, venous volume and arterial blood flow. Circulation $\mathbf{5 2}$ 141-145 (1975)

245. Briers, J. D. Laser speckle contrast analysis (LASCA): a nonscanning, full-field technique for monitoring capillary blood flow. J. Biomed. Opt. 1 174 (1996).

246. Intaglietta, M., Silverman, N. R. \& Tompkins, W. R. Capillary flow velocity measurements in vivo and in situ by television methods. Microvasc. Res. 10 165-179 (1975)

247. Ivanov, K. P. Kalinina, M. K \& Levkovich, Yu. I. Blood flow velocity in capillaries of brain and muscles and its physiological significance. Microvasc. Res. 22, 143-155 (1981)

248. Miller, J. S. et al. Rapid casting of patterned vascular networks for perfusable engineered three-dimensional tissues. Nat. Mater. 11, 768-774 (2012).

249. Grigoryan, B. et al. Multivascular networks and functional intravascular topologies within biocompatible hydrogels. Science 364, 458-464 (2019).

250. Dondossola, E. et al. Intravital microscopy of osteolytic progression and therapy response of cancer lesions in the bone. Sci. Transl. Med. 10, eaao5726 (2018).

251. Price, T. T. et al. Dormant breast cancer micrometastases reside in specific bone marrow niches that regulate their transit to and from bone. Sci. Transl. Med. 8, 340ra73 (2016).
252. He, W., Wang, H., Hartmann, L. C., Cheng, J.-X. \& Low, P. S. In vivo quantitation of rare circulating tumor cells by multiphoton intravital flow cytometry. Proc. Natl Acad. Sci. USA 104, 11760-11765 (2007).

253. Hodgkinson, C. L. et al. Tumorigenicity and genetic profiling of circulating tumor cells in small-cell lung cancer. Nat. Med. 20, 897-903 (2014).

254. Girotti, M. R. et al. Application of sequencing, liquid biopsies, and patient-derived xenografts for personalized medicine in melanoma. Cancer Discov. 6 286-299 (2016)

255. Pereira-Veiga, T. et al. CTCs-derived xenograft development in a triple negative breast cancer case. Int. J. Cancer 144, 2254-2265 (2019).

256. Greystoke, A. et al. Development of a circulating miRNA assay to monitor tumor burden: from mouse to man. Mol. Oncol. 10, 282-291 (2016).

257. Vishnoi, M. et al. Targeting USP7 identifies a metastasis-competent state within bone marrowresident melanoma CTCs. Cancer Res. 78, 5349-5362 (2018).

258. Williamson, S. C. et al. Vasculogenic mimicry in small cell lung cancer. Nat. Commun. 7, 13322 (2016)

259. Gkountela, S. et al. Circulating tumor cell clustering shapes DNA methylation to enable metastasis seeding. Cell 176, 98-112.e14 (2019).

260. Lee, A. M., Tormoen, G. W., Kanso, E., McCarty, O. J. T. $\&$ Newton, P. K. Modeling and simulation of procoagulant circulating tumor cells in flow. Front. Oncol. 2, 108 (2012).

261. Harlepp, S., Thalmann, F., Follain, G., Goetz, J. G. $\&$ Therry, M. Hemodynamic forces can be accurately measured in vivo with optical tweezers. Mol. Biol. Cell 28, 3252-3260 (2017)

262. Meng, F. \& Sachs, F. Visualizing dynamic cytoplasmic forces with a compliance-matched FRET sensor. J. Cell Sci. 124, 261-269 (2011).

263. Verma, D. et al. Interplay between cytoskeletal stresses and cell adaptation under chronic flow. PLOS ONE 7, e44167 (2012).

264. Ye, N. et al. Direct observation of $\alpha$-actinin tension and recruitment at focal adhesions during contact growth. Exp. Cell Res. 327, 57-67 (2014).

265. Yamashita, S., Tsuboi, T., Ishinabe, N., Kitaguchi, T. $\&$ Michiue, T. Wide and high resolution tension measurement using FRET in embryo. Sci. Rep 6 28535 (2016)

266. Conway, D. E. et al. Fluid shear stress on endothelial cells modulates mechanical tension across VE-cadherin and PECAM-1. Curr. Biol. 23 1024-1030 (2013).

267. Cai, D. et al. Mechanical feedback through E-cadherin promotes direction sensing during collective cell migration. Cell 157, 1146-1159 (2014).

268. Stabley, D. R., Jurchenko, C., Marshall, S. S. \& Salaita, K. S. Visualizing mechanical tension across membrane receptors with a fluorescent sensor. Nat. Methods 9, 64-67 (2012).

269. Arsenovic, P. T. \& Conway, D. E. in The LINC Complex (eds Gundersen, G. G. \& Worman, H. J.) 1840, 59-71 (Springer, 2018).

270. Arsenovic, P. T. et al. Nesprin-2G, a component of the nuclear LINC complex, is subject to myosin-dependent rension. Biophys. J. 110, 34-43 (2016)

271. Arsenovic, P. T., Bathula, K. \& Conway, D. E. A protoco for using Förster resonance energy transfer (FRET)force biosensors to measure mechanical forces across the nuclear LINC complex. J. Vis. Exp. https://doi.org/ 10.3791/54902 (2017)

272. Seong, J. et al. Visualization of src activity at different compartments of the plasma membrane by FRET imaging. Chem. Biol. 16, 48-57 (2009).
273. Seong, J. et al. Detection of focal adhesion kinase activation at membrane microdomains by fluorescence resonance energy transfer. Nat. Commun. 2, 406 (2011).

274. Itoh, R. E. et al. Activation of Rac and Cdc42 video imaged by fluorescent resonance energy transferbased single-molecule probes in the membrane of living cells. Mol. Cell. Biol. 22, 6582-6591 (2002).

275. Yoshizaki, H. et al. Activity of Rho-family GTPases during cell division as visualized with FRET-based probes. J. Cell Biol. 162, 223-232 (2003).

276. Johnsson, A.-K. E. et al. The rac-FRET mouse reveals tight spatiotemporal control of rac activity in primary cells and tissues. Cell Rep. 6, 1153-1164 (2014).

277. Nobis, M. et al. A rhoA-FRET biosensor mouse for intravital imaging in normal tissue homeostasis and disease contexts. Cell Rep. 21, 274-288 (2017).

278. Antonacci, G. \& Braakman, S. Biomechanics of subcellular structures by non-invasive Brillouin microscopy. Sci. Rep. 6, 37217 (2016).

279. Palombo, F. et al. Biomechanics of fibrous proteins of the extracellular matrix studied by Brillouin scattering J. R. Soc. Interface 11, 20140739 (2014).

280. Palombo, F., Madami, M., Stone, N. \& Fioretto, D. Mechanical mapping with chemical specificity by confocal Brillouin and Raman microscopy. Analyst 139, 729-733 (2014).

\section{Acknowledgements}

D.H. acknowledges support from the Cancer Institute of New South Wales (CINSW) Fellowship and project grants from the National Breast Cancer Foundation (NBCF), St. Vincent's Clinic Foundation and Sydney Catalyst (the Translational Cancer Research Centre of central Sydney and regional New South Wales). S.W. acknowledges support from National Health and Medical Research Council (NHMRC) Project Grants and Suttons. P.T. acknowledges support from an NHMRC fellowship, NHMRC project grants and a Len Ainsworth Pancreatic Cancer Fellowship. This project was made possible by an Avner Pancreatic Cancer Foundation Grant. The authors thank all members of the Goetz Lab for helpful discussions. Work related to this Review in the Goetz Lab (G.F., N.O., V.H., S.H. and J.G.G.) is funded by the French National Cancer Institute (INCa) and Plan Cancer, and by institutional funds from INSERM and the University of Strasbourg. N.O. acknowledges support from Plan Cancer 2014-2019 (OptoMetaTrap) and the Association pour la Recherche Contre le Cancer (ARC). G.F. is supported by La Ligue Contre le Cancer and the University of Strasbourg.

\section{Author contributions}

G.F. D.H. N.O. S.H. V.H. P.T and J.G.G researched data for the article. All authors made substantial contributions to the discussion of content, wrote the manuscript and reviewed and/or edited the manuscript before submission.

\section{Competing interests}

The authors declare no competing interests.

\section{Peer review information}

Nature Reviews Cancer thanks D. Wirtz and the other, anonymous, reviewer(s) for their contribution to the peer review of this work.

\section{Publisher's note}

Springer Nature remains neutral with regard to jurisdictional claims in published maps and institutional affiliations.

\section{Supplementary information}

Supplementary information is available for this paper at https://doi.org/10.1038/s41568-019-0221-x.

(c) Springer Nature Limited 2019 